\title{
Los cambios de la pobreza en Argentina: un análisis de descomposiciones *
}

\author{
Jessica Bracco** \\ Tesis de Maestría \\ Maestría en Economía \\ Universidad Nacional de La Plata
}

Director de Tesis: Leonardo Gasparini

Mayo, 2018

Códigos JEL: C15, D31, D33, I32, J31

\footnotetext{
* Este trabajo constituye la tesis de Maestría en Economía de la UNLP, realizada bajo la dirección de Leonardo Gasparini, a quien agradezco todo el tiempo, guía y apoyo a lo largo de este proceso. Agradezco además la valiosa ayuda de Leopoldo Tornarolli y Javier Alejo y a los participantes del seminario de tesis de la Maestría en Economía de la UNLP. Los eventuales errores son de mi exclusiva responsabilidad.

${ }^{* *}$ Centro de Estudios Distributivos Laborales y Sociales (CEDLAS), Facultad de Ciencias Económicas, Universidad Nacional de La Plata. Email: jbracco@gmail.com.
} 


\section{Resumen}

Este trabajo utiliza tres metodologías de descomposición con el objetivo de analizar los posibles determinantes del cambio en la pobreza en Argentina, en el período 2003-2015. Se emplea, en primer lugar, una extensión de la metodología de Datt y Ravallion (1992), que descompone los cambios en la pobreza en un efecto crecimiento y uno redistribución. En segundo lugar, la metodología de Azevedo, Nguyen y Sanfelice (2006), que permite separar el peso relativo de las distintas fuentes de ingresos. Por último, la descomposición de Bourguignon, Ferreira y Lustig (2005), que permite medir la relevancia de distintos factores que podrían haber influido en el cambio de la pobreza. Los resultados del trabajo sugieren que durante una primera etapa (2003-2007) fueron fundamentalmente las mejoras en el mercado laboral las principales responsables del importante ritmo de reducción de la pobreza. En una segunda etapa (2007-2011), en la que la reducción fue más modesta, la contribución del mercado laboral fue pequeña y la caída fue impulsada principalmente por las transferencias estatales y por cambios en características de la población (expansión educativa y disminución de la fecundidad). Finalmente, el período 2011-2015 fue de estancamiento general, y ningún factor parece haber podido contribuir a la reducción de la pobreza.

Palabras clave: Pobreza, Descomposición, Argentina.

\section{Abstract}

This paper uses three decomposition methodologies with the objective of analyzing the possible determinants of the change in poverty in Argentina, in the period 2003-2015. First, an extensión of the methodology of Datt and Ravallion (1992) is used, which decomposes the changes in poverty into an effect of growth and redistribution. Secondly, the methodology of Azevedo, Nguyen and Sanfelice (2006), which allows to separate the relative weight of the different sources of income. Finally, the decomposition of Bourguignon, Ferreira and Lustig (2005), which allows to measure the relevance of different factors that could have influenced the change in poverty. The results of the study suggest that during the first stage (2003-2007) improvements in the labor market were mainly responsible for the important rate of poverty reduction. In a second stage (20072011), in which the reduction was more modest, the contribution of the labor market was small and the fall was driven mainly by public transfers and by changes in population characteristics (educational expansion and decrease in fertility). Finally, the period 20112015 was one of general stagnation, and no factor seems to have been able to contribute to the reduction of poverty.

Key Words: Poverty, Decomposition, Argentina. 


\section{Introducción}

La pobreza es posiblemente el problema de mayor relevancia social. El acuerdo acerca de la necesidad de combatirla es tan generalizado que muchos países y organismos internacionales la han fijado como objetivo prioritario. Las Naciones Unidas, en su declaración de Objetivos de Desarrollo del Milenio, propuso como meta mundial número uno la reducción a la mitad de la pobreza en cada país entre 1990 y 2015. En los nuevos Objetivos de Desarrollo Sostenible de las Naciones Unidas, aceptados por todos los países del mundo, la meta número uno para 2030 es "erradicar la pobreza extrema para todas las personas en el mundo" y la número dos es "hambre cero". De igual forma, el lema central del Banco Mundial, el organismo de crédito en el que participan casi todos los países del mundo, es "Por un mundo sin pobreza". Estas declaraciones reflejan el lugar central que ocupa la preocupación por la pobreza, aun por sobre otros problemas sociales como la desigualdad o el desempleo.

Estudiar la pobreza no solo es importante por tratarse de un fenómeno preocupante, sino también por sus potenciales consecuencias sobre otras variables económicas y sociales relevantes. La pobreza puede condicionar seriamente la posibilidad de acumular capital humano $\mathrm{y}$ otros factores productivos $\mathrm{y}$, por lo tanto, afectar negativamente las perspectivas de crecimiento económico.

Más allá del interés por medir esta problemática social, existe también la necesidad de responder a ciertos interrogantes que nos permitan entender el fenómeno de la pobreza, como cuáles son los determinantes de un cambio de la misma, en un período particular. Existe un acuerdo de la estrecha relación que esta medida mantiene con el crecimiento económico, pero ¿cuánto del crecimiento en el empleo es responsable de los cambios experimentados en la pobreza? ¿cuál es el rol del aumento del salario real, de las transferencias del gobierno o de los cambios demográficos?

El objetivo de este trabajo es analizar los cambios en la pobreza para el período comprendido entre el año 2003 y el año 2015 en Argentina, caracterizado por mejoras en una gran cantidad de indicadores sociales. Luego de la fuerte crisis macroeconómica sufrida en 2001/2002, el ingreso per cápita real de una familia promedio aumentó de $\$ 3050$ en 2003 a $\$ 4684$ en 2015, lo que implicó un aumento de aproximadamente 54\% ${ }^{1}$.

\footnotetext{
${ }^{1}$ Ingreso per cápita familiar en pesos constantes de 2015.
} 
La desigualdad, medida mediante el coeficiente de Gini, se redujo de 0.51 a comienzos del período a 0.41 , una caída de 10 puntos. El desempleo por su parte, cayó de $15.4 \%$ a $6.9 \%$ entre los años 2003 y 2015. Bajo este panorama, una medida usual de pobreza, la tasa de incidencia a 4 dólares, experimentó una considerable caída de aproximadamente 23 puntos: de 32.5 en 2003 a 9.5 en 2015 .

Este trabajo hace una aproximación al estudio de los determinantes de la dinámica de la pobreza en Argentina durante el período 2003-2015 mediante la aplicación de metodologías de descomposición. Las mismas tienen su origen en los trabajos de Oaxaca (1973) y Blinder (1973), quienes buscaban originalmente descomponer los cambios en salarios a lo largo del tiempo. Desde entonces, el aumento en la desigualdad salarial observado en Estados Unidos y otros países desde finales de 1970 ha llevado al desarrollo de nuevos métodos, incluidos los introducidos por Datt y Ravallion (1992), Juhn, Murphy y Pierce (1993), Bourguignon, Ferreira y Lustig (2005) y Barros, Carvalho, Franco y Mendoça (2006), entre otros. Pese a que algunos de estos métodos fueron diseñados principalmente para comprender cambios en la desigualdad, también pueden ser utilizados para entender cambios en la pobreza.

En particular, el trabajo realiza tres descomposiciones para explicar cambios en la pobreza. Una primera descomposición consiste en establecer cuál es el aporte del crecimiento económico a los cambios en la pobreza y en qué medida ese efecto se ve reforzado o contrarrestado por los cambios en la desigualdad. De esta forma, en una primera instancia se separará el cambio en algunos de los índices de pobreza más utilizados en la literatura en un efecto crecimiento y un efecto redistribución. En estudios de esta naturaleza, Datt y Ravallion (1992) utilizan esta metodología para descomponer los cambios en la pobreza de Brasil e India en los 80; Kolenikov y Shorrocks (2000) analizan la situación de Rusia en los 80 y 90 e Inchauste, et al. (2014) hacen lo propio para 21 países de América Latina en los 2000s, en un trabajo para el Banco Mundial. En su análisis, los autores incluyen a Argentina en el período 2000-2010 y encuentran que, en la reducción de la pobreza en ese período, el efecto redistribución es el mayor responsable, dando cuenta de aproximadamente el $60 \%$ de la caída, mientras que el $40 \%$ restante corresponde al efecto crecimiento. Estos resultados, sin embargo, podrían verse afectados si se tiene en cuenta que ese período de 10 años no es homogéneo. Por esto mismo, uno de los ejercicios propuestos en este trabajo es realizar esta descomposición 
separando por etapas claramente diferenciadas, y extendiendo el análisis a años más actuales.

A pesar de que la descomposición entre efecto crecimiento y efecto redistribución ha sido ampliamente utilizada en la literatura, es limitante en el sentido de que, si bien permite determinar el rol del crecimiento en los cambios de la pobreza, no es informativa acerca del impacto específico de algunas variables, como los salarios o las políticas de transferencias del gobierno. La segunda descomposición que se realiza en el trabajo es la propuesta por Azevedo, Nguyen y Sanfelice (2012), que permite separar el peso relativo de los ingresos laborales versus las transferencias monetarias sobre la pobreza, así como también el de los cambios demográficos de la población. Los autores, que proponen una extensión a la descomposición de Barros, Carvalho, Franco y Mendoça (2006), solucionan el problema de path dependence del que sufren este tipo de metodologías ${ }^{2}$. Azevedo, Inchauste y Sanfelice (2013) utilizan este método para descomponer la desigualdad para algunos países de América Latina. Vargas y Garriga (2015) por su parte, realizan este ejercicio para estudiar la reducción de la desigualdad y la pobreza en Bolivia. Por último, Azevedo et al. (2013) e Inchauste et al. (2014) utilizan variantes de este método para descomponer los cambios en la pobreza en América Latina. En el caso de Argentina, para el período analizado de 2000 a 2010 los autores encuentran que, de los 13 puntos de reducción de la pobreza, el 35\% corresponde al aumento de los ingresos laborales, seguido por las pensiones (15\%) y las transferencias (7.3\%). La descomposición que se realiza más adelante busca responder si estos resultados, generales para el período 2000-2010, se mantienen al desagregar por etapas, incluyendo algunos años más en el análisis.

Por último, la descomposición de Bourguignon et al. (2005) permite medir la relevancia de varios factores que podrían haber influido en el cambio de la pobreza. En particular, esta metodología permite separar los efectos producidos por cambios en las dotaciones de la población (como cambios en la estructura educativa o poblacional), cambios generados en los retornos a aquellas dotaciones (como el pago a la educación) y cambios en factores no observables (como la habilidad). Gasparini, Marchionni y Sosa Escudero (2005) aplican esta metodología para estudiar los cambios en la desigualdad en el Gran

\footnotetext{
${ }^{2}$ El problema de Path dependence en los ejercicios de descomposición hace referencia a los distintos resultados que pueden obtenerse en las simulaciones para un mismo cambio, dependiendo de la secuencia en la que estas se realizan.
} 
Buenos Aires durante el período 1986-1998. Ferreira y Paes de Barros (1999) descomponen los cambios en la pobreza de las áreas urbanas de Brasil entre los años 1976 y 1996. Por último, Inchauste et al. (2014) utilizan esta metodología para estudiar los cambios en la pobreza para Bangladés, Perú y Tailandia.

Las metodologías mencionadas serán explicadas más detalladamente en las páginas siguientes. Sin embargo, es importante dar cuenta que todas ellas sufren de inconsistencia en el equilibrio, ya que se basan en simulaciones de la distribución del ingreso que no reflejan un equilibrio económico general. Representan más bien un ejercicio estadístico, en el que se asume que es posible modificar un potencial determinante, por ejemplo, los salarios, y mantener todo lo demás constante. De todos modos, y a pesar de que este tipo de metodologías no permiten una interpretación causal, representan una herramienta útil para identificar regularidades empíricas en el cambio de la pobreza que permitan contextualizar e informar la discusión sobre los potenciales efectos que podrían tener ciertas políticas públicas sobre algunos de los determinantes estudiados.

El resto del trabajo está organizado de la siguiente manera: en la sección 2 se describen los datos utilizados y la evolución de la pobreza en Argentina. En la sección 3 se describen las tres metodologías de descomposición con las cuales se analizan los cambios en los índices de pobreza, cuyos resultados se muestran en la sección 4. Por último, se cierra el trabajo con algunos comentarios, en la sección 5.

\section{Datos y estadísticas descriptivas}

\subsection{Datos}

Los datos que se utilizan en este trabajo provienen de la Encuesta Permanente de Hogares (EPH) de Argentina. Esta encuesta, llevada a cabo por el Instituto Nacional de Estadística y Censos (INDEC) desde el año 1974, es la encuesta de hogares más representativa del país. Inicialmente la EPH se realizaba solamente en el Gran Buenos Aires, extendiéndose luego a todos los aglomerados urbanos de más de 100 mil habitantes. Actualmente cubre las 31 mayores áreas urbanas del país, en las cuales habita alrededor del 70\% de la población urbana de Argentina. Dado que el porcentaje de esta población en el país es del $87 \%$, la muestra de la EPH representa cerca del $60 \%$ de la población total argentina. Si bien desde sus comienzos fue una encuesta de modalidad puntual, con dos rondas anuales 
en mayo y octubre, desde el año 2003 el INDEC implementó importantes cambios metodológicos, entre los que se cuentan modificaciones en el cuestionario de la encuesta y en el período de captación de la información, cambios en el esquema de rotación de la muestra de panel e imputaciones a las observaciones sin respuesta en las preguntas de ingreso. Desde entonces la encuesta es realizada a lo largo de todo el año y publicada por trimestres y se la conoce como Encuesta Permanente de Hogares Continua.

Recientemente el INDEC, que sufría problemas de credibilidad en sus datos y estadísticas publicadas, retomó la publicación de datos de pobreza e indigencia, interrumpida en 2015. La nueva metodología adoptada desde 2016 no es comparable con la que se aplicaba hasta 2015. Las diferencias no provienen sólo del uso de una serie de precios más creíble, sino que son el resultado del cambio en un conjunto de decisiones técnicas que afectan la definición de la canasta básica y del coeficiente de Orshansky, que permite calcular la línea de pobreza a partir de la línea de indigencia (CEDLAS, 2017). Además, el instituto de estadística realizó cambios relativos a la imputación por no respuesta, relacionado con modificaciones en el factor de ponderación de la encuesta de hogares. Todos estos cambios marcan el fin de una etapa metodológica iniciada en el año 2003, que coincide además con un período político bien definido, comenzado también en 2003 y finalizado en el año 2015, con el inicio de una nueva administración en el gobierno nacional.

Este trabajo toma como ventana temporal de análisis ese período de tiempo: desde el segundo semestre de 2003, que representa el comienzo de la modalidad continua de la EPH al primer semestre de 2015, nuevo momento de inflexión en el funcionamiento del instituto de estadísticas argentino. Es posible dividir este período en tres etapas de cuatro años de duración cada una, claramente diferenciadas en términos de evolución de la pobreza, entre otros indicadores. La primera etapa abarca desde el segundo semestre de 2003 al primer semestre de 2007, y está marcada por un fuerte descenso en los indicadores de pobreza. La siguiente etapa, del primer semestre de 2007 al primer semestre de 2011 está caracterizada por una desaceleración en la caída de muchos indicadores sociales, en particular los referentes al fenómeno estudiado en este trabajo. Finalmente, la tercera y última etapa, que va del primer semestre de 2011 al primer semestre de 2015, es una etapa de claro estancamiento en los indicadores de pobreza.

Cabe aclarar que, dado que los ejercicios siguientes requieren de la interacción de las encuestas de la EPH para cada año elegido, con el objetivo de lograr homogeneidad en las bases utilizadas se eliminan las observaciones pertenecientes a San Nicolás- Villa 
Constitución, Rawson- Trelew y Viedma- Carmen de Patagones, debido a que estos aglomerados no estaban incorporados a la base del año 2003.

\subsection{La evolución de la pobreza}

Entre 2003 y 2015 la tasa de incidencia de la pobreza sufrió una considerable caída. La reducción fue de aproximadamente 23 puntos, cuando la pobreza se mide con la línea de 4 dólares por día por persona a paridad de poder adquisitivo (PPA). La trayectoria de la tasa de pobreza sin embargo no ha sido homogénea a lo largo de todo el período. De hecho, es posible identificar tres etapas claramente diferenciadas, de aproximadamente cuatro años cada una. La primera de ellas, de 2003 a 2007, caracterizada por fuertes mejoras sociales y laborales explicadas en parte por la recuperación de la fuerte crisis macroeconómica sufrida en 2001/2002 y en parte por un conjunto de razones ampliamente discutidas en la literatura, como políticas sociales, precio de los comodities, etc. (Gasparini y Cruces, 2008), estuvo marcada por un descenso acelerado de la pobreza. La tasa de incidencia pasó de 32.5 en 2003 a 17.4 en 2007, lo que implica una importante caída de 3.8 puntos promedio por año (Figura 2.1).

Durante la siguiente etapa de cuatro años, las mejoras sociales se desaceleraron, posiblemente como resultado en parte del fin del efecto rebote de la crisis de 2001 y el impacto de la crisis internacional de 2008/2009. La tasa de pobreza, si bien se redujo, lo hizo a un ritmo más moderado: 1.4 puntos por año.

Por último, la etapa 2011-2015 se caracterizó por un claro estancamiento en los indicadores sociales. La tasa de pobreza en 2015 (9.47) fue de hecho superior a la de unos años atrás (8.86 en 2013). El ritmo de reducción de la pobreza en este tramo fue casi nulo, de 0.3 puntos por año. 
Figura 2.1. Tasa de pobreza moderada en Argentina, 2003-2015.

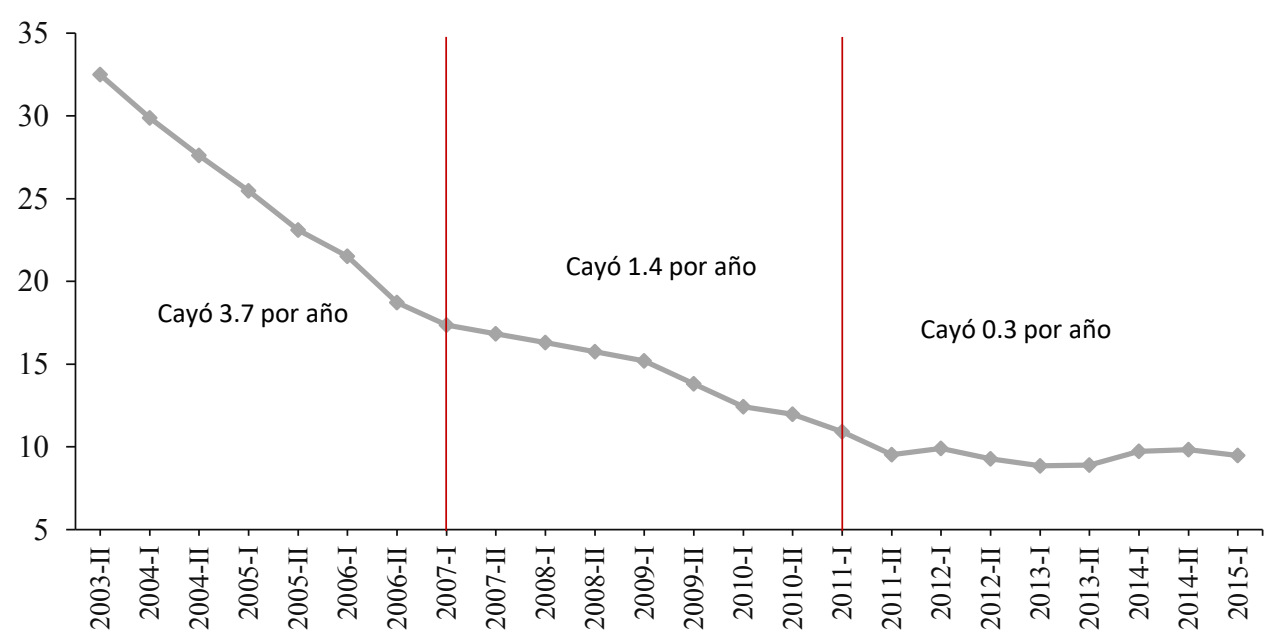

Nota: Tasa de pobreza calculada en base al ingreso per cápita familiar. Línea de pobreza de 4 dólares por día por persona a PPA.

Fuente: Elaboración propia en base a datos de la EPHC.

En el contexto de América Latina la línea de 4 dólares por día es usualmente utilizada para definir pobreza "moderada" (Gasparini et al., 2013). Por su parte, la línea de 2 dólares por día es comúnmente aplicada para estudiar situaciones de pobreza "extrema". La evolución de la pobreza extrema (línea de 2 dólares) es muy similar a la experimentada por la pobreza moderada (línea de 4 dólares). Como puede verse en la Figura 2.2, a la salida de la crisis, el 19\% de los argentinos estaban en situación de pobreza extrema. Poco más de una década después, este valor se redujo a 3\%, lo que implica una caída total de 16 puntos. Pero como sucedió con la pobreza a 4 dólares, esta reducción no fue constante a través de los años. Durante el primer tramo la caída fue considerable: 2.5 puntos por año. En el segundo subperíodo, entre 2007 y 2011, la caída se desaceleró, pasando a un ritmo de 1 punto por año. Finalmente, la reducción de la pobreza extrema en el último tramo fue casi nula, de 0.3 puntos por año. Esta evolución no homogénea de la pobreza medida con las líneas internacionales de 2 y 4 dólares diarios es documentada también en Tornarolli (2018), quien emplea una metodología comparable en el tiempo para las medidas de pobreza e indigencia oficiales ${ }^{3}$.

\footnotetext{
${ }^{3}$ En 2016 el INDEC, que había sufrido de pérdida de credibilidad en la publicación de las estadísticas durante el período 2007-2015, retomó la publicación de series oficiales de indigencia y pobreza, que se había interrumpido en 2013. Dado que los cambios en las decisiones metodológicas empleadas arrojan resultados para 2016 y 2017 que no son directamente comparables a los publicados hasta 2013 por el INDEC, Tornarolli (2018) construye series comparables de pobreza e indigencia oficiales para el período completo.
} 
Figura 2.2. Tasa de pobreza extrema en Argentina, 2003-2015.

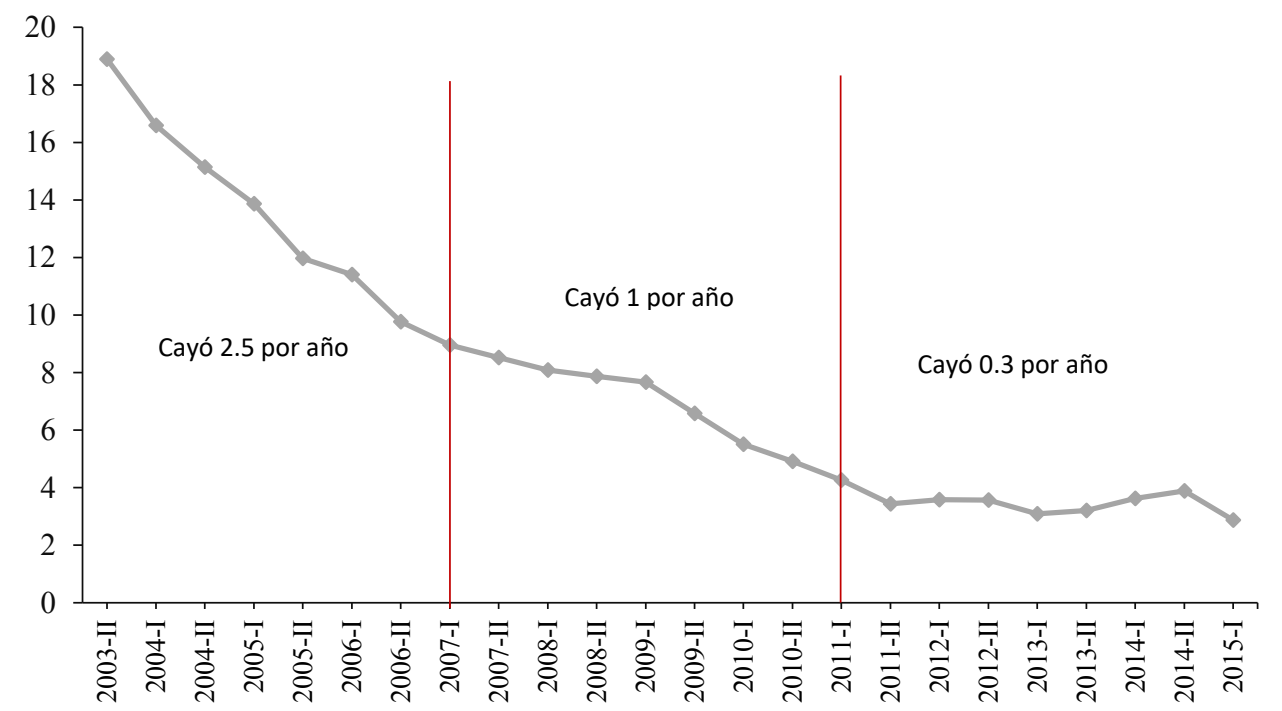

Nota: Tasa de pobreza calculada en base al ingreso per cápita familiar. Línea de pobreza de 2 dólares por día por persona a PPA.

Fuente: Elaboración propia en base a datos de la EPHC.

\subsection{Robustez}

El análisis de la evolución de la pobreza es robusta a la utilización de distintos indicadores para medir la misma. Foster, Greer y Thorbecke (1984) proponen una familia de indicadores de pobreza que en términos discretos toma la forma:

$$
F G T(\alpha)=\frac{1}{N} \sum_{i=1}^{N}\left(1-\frac{x_{i}}{z}\right)^{\alpha} 1\left(x_{i}<z\right), \alpha \geq 0
$$

donde $N$ es la población, $x_{i}$ el ingreso individual, $z$ un umbral de pobreza a partir del cual se considera a un individuo como no pobre y $1\left(x_{i}<z\right)$ una función indicadora que vale 1 si el ingreso del individuo no logra superar el umbral, o línea de pobreza $z$. Finalmente, $\alpha$ define la estructura con la que se pondera a cada individuo pobre para alcanzar el índice agregado, por lo que existe un índice de pobreza FGT para cada valor de este parámetro. Cuando $\alpha=0$ todos los individuos pobres se ponderan de la misma forma en el índice y el $F G T(0)$ coincide con la tasa de incidencia. Estos son los datos que se muestran en las Figuras 2.1 y 2.2 para dos líneas de pobreza alternativas de 4 y 2 dólares diarios, respectivamente. Cuando $\alpha=1$ el indicador tiene en cuenta la brecha individual que cada persona cuyo ingreso no supera cierto umbral tiene respecto al mismo, por lo que el $F G T(1)$ es conocido como el indicador de brecha de la pobreza. Cuando $\alpha>1$, la función $\left(1-x_{i} / z\right)^{\alpha}$ se vuelve convexa, por lo que el "aporte" de los individuos más pobres se 
hace proporcionalmente más grande: el indicador le da particular relevancia al nivel de vida de los más pobres. En la práctica, se utiliza $\alpha=2$. El FGT(2) es conocido como indicador de "profundidad" o "severidad" de la pobreza, o índice de brecha cuadrática de la pobreza ${ }^{4}$.

En el caso argentino, entre 2003 y 2015, el patrón que sigue la tasa de pobreza o FGT(0) es compartido por la brecha de la pobreza o FGT(1) y por la severidad de la pobreza o FGT(2). La Figura 2.3 muestra la evolución de estos últimos dos indicadores para una línea de pobreza de 4 dólares por día, a PPA. En la primera etapa, la brecha y severidad de la pobreza pasaron de 14.6 y 8.8 respectivamente en 2003 a 7 y 4.2 en 2007, lo que implica una reducción de casi 2 puntos por año en el primer caso y 1 punto por año en el segundo. Como en el caso de la tasa de pobreza, en la segunda etapa la reducción resultó más modesta: el FGT(1) cayó 0.7 puntos por año en promedio (7 en 2007 a 3.7 en 2011), mientras que el FGT(2) lo hizo en 0.5 puntos (4.2 en 2007 a 1.9 en 2011), por lo que ambas medidas redujeron su ritmo de crecimiento a la mitad, o incluso más. Finalmente, la tercera etapa es de estancamiento en la reducción de la brecha de la pobreza así como también de la severidad. En la figura puede verse como ambas series se tornan prácticamente horizontales desde el año 2011.

Figura 2.3. Brecha y severidad de la pobreza en Argentina, 2003-2015.

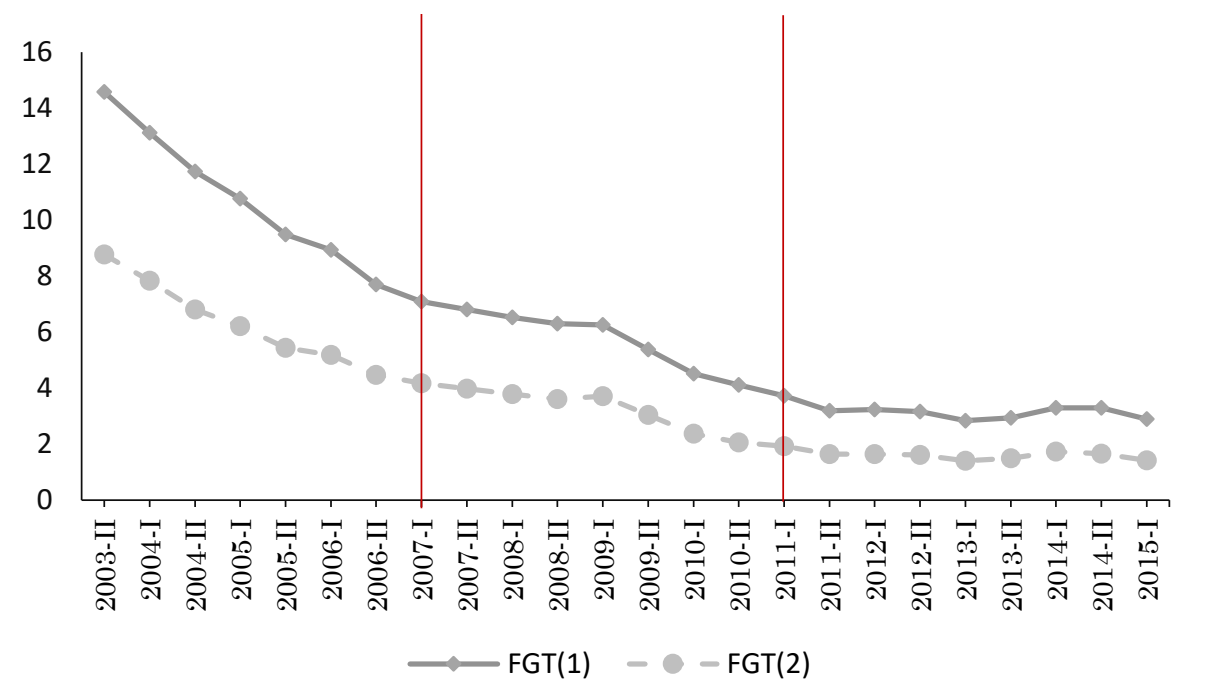

Nota: Brecha y severidad de la pobreza calculadas en base al ingreso per cápita familiar. Línea de pobreza de 4 dólares por día por persona a PPA.

Fuente: Elaboración propia en base a datos de la EPHC.

\footnotetext{
${ }^{4}$ Para una explicación más detallada de estos índices de pobreza ver Gasparini et al (2013)
} 
El segundo objetivo del trabajo apunta a responder qué factores intervinieron en estas caídas heterogéneas de la pobreza en Argentina. Por lo tanto, lo que sigue es un análisis de los posibles determinantes, realizado en base a metodologías de descomposiciones.

\section{Metodología}

Esta sección explica la metodología detrás de las microdescomposiciones realizadas sobre los cambios en la pobreza. En primer lugar, se realizará una descomposición simple del cambio en un efecto crecimiento y un efecto redistribución. Luego, con el objetivo de profundizar en el análisis de los determinantes, se realizará una segunda descomposición por componentes del ingreso del hogar, para separar el peso relativo de, por ejemplo, los ingresos por salario de los ingresos por transferencias estatales. Finalmente, se analizarán los determinantes de los ingresos salariales de los trabajadores, separando los efectos de dotación (tanto inobservables como observables) de los efectos retorno de esas dotaciones.

\subsection{Descomposición de la pobreza en efecto crecimiento y efecto redistribución}

Un procedimiento muy simple de descomposición consiste en examinar cómo el crecimiento económico contribuye a la reducción de la pobreza en el tiempo y ver a la vez hasta qué punto el impacto del mismo se ve reforzado o atenuado por los cambios en la desigualdad de ingresos. De esta forma, los cambios en la pobreza de un período a otro pueden descomponerse en un efecto crecimiento y un efecto redistribución, que es la metodología propuesta por Datt y Ravallion (1992). En su forma original, esta descomposición incluye un término residual y el valor de los efectos depende del período elegido como base o referencia. Para resolver este problema, la práctica estándar es calcular la descomposición en ambos sentidos y luego tomar el promedio (Gasparini et al., 2013, Inchauste et al. 2014).

La descomposición del cambio en la pobreza puede verse en la Figura 3.1 ${ }^{5}$. En ella, la distribución del ingreso cambia de $f(x)$ a $g(x)$, por lo que la pobreza cae (notar que el área de $f(x)$ a la izquierda de la línea de pobreza $z$ es mayor a la de $g(x)$ ). Este cambio puede dividirse de manera artificial en dos pasos. El primero asume un aumento proporcional de todos los ingresos, por lo que la distribución se desplaza hacia la derecha,

\footnotetext{
${ }^{5}$ La explicación que sigue está tomada de Gasparini et al. (2013).
} 
indicando un ingreso medio mayor. Esta nueva distribución $f^{*}(x)$ es una distribución contrafáctica cuyo ingreso medio es igual al de $g(x)$. El paso de $f$ a $f^{*}$ es el efecto crecimiento y su impacto sobre el nivel de pobreza es el área A. El segundo paso de la descomposición, es el desplazamiento de $f^{*}(x)$ a $g(x)$, que capta el impacto del cambio en la forma de la distribución, con la media inalterada. Esto es el efecto que la redistribución tiene sobre la pobreza, que puede verse en la figura como el área sombreada B.

Figura 3.1. Descomposición del cambio en la pobreza.

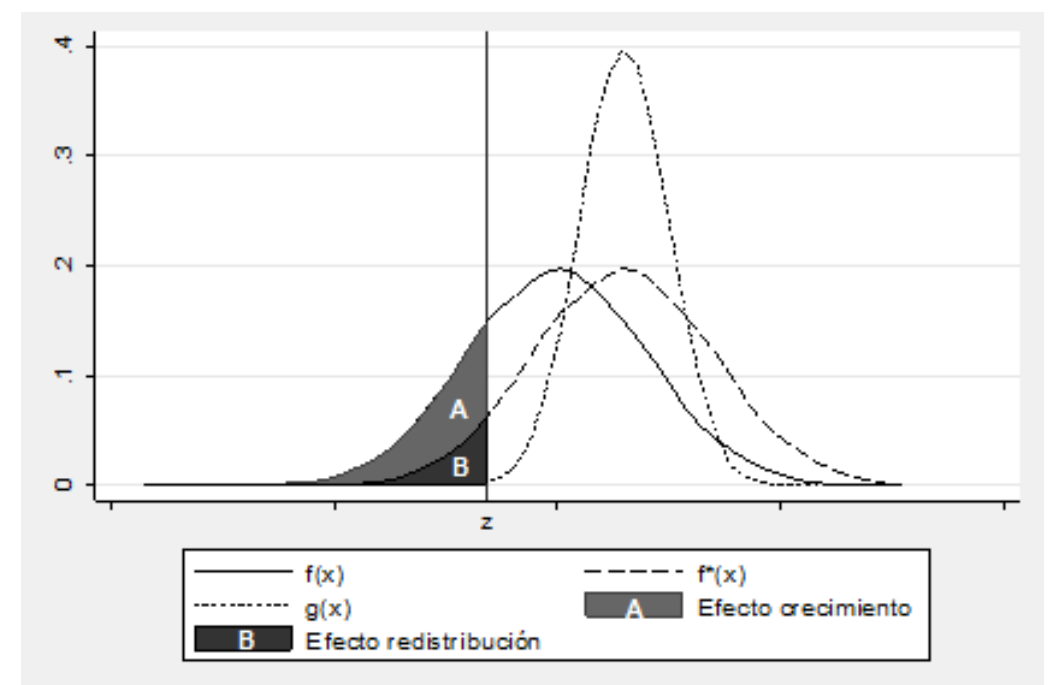

Fuente: Gasparini, Cicowiez y Sosa Escudero (2013)

De esta forma, es posible expresar la pobreza como el resultado de la interacción de una línea de pobreza $z$, el ingreso medio $\mu$ y la forma de la distribución, captada por su curva de Lorenz, $L(p)$, por lo que la pobreza es:

$$
P=P(\mu, L(p), z)
$$

De acuerdo con esta ecuación, dada una línea de pobreza $z$, los cambios en la pobreza pueden deberse a cambios en el ingreso medio $\mu$, a cambios en la forma de la distribución $L(p)$, o a ambos. Denotando con $\Delta P$ al cambio en la pobreza entre el momento $t_{1} \mathrm{y}$ el momento $t_{2}$ y asumiendo que la línea de pobreza $z$ no cambia, es posible escribir:

$$
\Delta P=P\left(\mu_{2}, L_{2}(p), z\right)-P\left(\mu_{1}, L_{1}(p), z\right)
$$

Si se suma y se resta a ambos términos $P\left(\mu_{1}, L_{2}(p), z\right)$, se obtiene que:

$$
\Delta P=\left[P\left(\mu_{2}, L_{2}(p), z\right)-P\left(\mu_{1}, L_{2}(p), z\right)\right]+
$$




$$
+\left[P\left(\mu_{1}, L_{2}(p), z\right)-P\left(\mu_{1}, L_{1}(p), z\right)\right]
$$

Así, la ecuación 3.3 muestra cómo cambios en la pobreza resultan de la suma de dos posibles cambios: el generado por una modificación en el ingreso medio, con la forma de la distribución constante (primer término, que capta el efecto crecimiento) y aquel generado por una modificación de la curva de Lorenz, ante un ingreso medio fijo (segundo término, que captura el efecto redistribución).

Este mismo ejercicio se podría realizar alterando los años base, de manera que el cambio en la pobreza también podría escribirse como:

$$
\begin{aligned}
\Delta P= & {\left[P\left(\mu_{2}, L_{1}(p), z\right)-P\left(\mu_{1}, L_{1}(p), z\right)\right]+} \\
& +\left[P\left(\mu_{2}, L_{2}(p), z\right)-P\left(\mu_{2}, L_{1}(p), z\right)\right]
\end{aligned}
$$

Un procedimiento usual es tomar el promedio de estas opciones para calcular ambos efectos. Escribiendo el cambio en la pobreza debido al efecto crecimiento como:

$$
\begin{aligned}
\Delta P_{C}= & \frac{1}{2}\left[P\left(\mu_{2}, L_{1}(p), z\right)-P\left(\mu_{1}, L_{1}(p), z\right)\right]+ \\
& +\left[P\left(\mu_{2}, L_{2}(p), z\right)-P\left(\mu_{1}, L_{2}(p), z\right)\right]
\end{aligned}
$$

y el correspondiente al efecto redistribución:

$$
\begin{aligned}
\Delta P_{R} & =\frac{1}{2}\left[P\left(\mu_{1}, L_{2}(p), z\right)-P\left(\mu_{1}, L_{1}(p), z\right)\right]+ \\
& +\left[P\left(\mu_{2}, L_{2}(p), z\right)-P\left(\mu_{2}, L_{1}(p), z\right)\right]
\end{aligned}
$$

Es posible expresar entonces el cambio en la pobreza en dos términos: el efecto crecimiento $\Delta P_{C}$ y el efecto redistribución, $\Delta P_{R}$ :

$$
\Delta P=\Delta P_{C}+\Delta P_{R}
$$

Como se sostuvo anteriormente, este tipo de metodología de descomposición representa una herramienta simple desde un punto de vista de implementación e interpretación. La misma permite determinar cuánto del cambio en la pobreza de un período a otro es atribuible al crecimiento económico y cuánto al cambio en la desigualdad. Sin embargo, poco explica sobre qué aspectos de ese crecimiento (los salarios, las jubilaciones, etc) o de esa redistribución (programas de transferencias, remesas, etc) son los responsables específicos de dicho cambio. 


\subsection{Descomposición de la pobreza por fuentes de ingresos}

La metodología propuesta por Azevedo, Nguyen y Sanfelice (2012) es una extensión de la descomposición desarrollada por Barros et al. (2006) que permite obtener una aproximación del peso relativo de los ingresos laborales versus los no laborales, así como también de los factores demográficos en la explicación del cambio en la pobreza.

Siguiendo a Barros et al. (2006), el ingreso per cápita del hogar se define como la suma de los ingresos individuales $y_{i}$ de quienes integran el hogar $h$, dividido la cantidad de miembros $n$ :

$$
Y_{p c}=\frac{Y_{h}}{n}=\frac{1}{n} \sum_{i=1}^{n} y_{i}
$$

Teniendo en cuenta que sólo los miembros mayores a 15 años, $n_{A}$, contribuyen al ingreso familiar, y que los ingresos individuales pueden ser separados en laborales $y_{i}^{L}$ y no laborales $y_{i}^{N L}$, la ecuación (3.8) puede escribirse como:

$$
Y_{p c}=\frac{n_{A}}{n}\left(\frac{1}{n_{A}} \sum_{i \in A}^{n} y_{i}^{L}+\frac{1}{n_{A}} \sum_{i \in A}^{n} y_{i}^{N L}\right)
$$

Por último, dentro del grupo de adultos, son los ocupados quienes llevan el ingreso laboral al hogar, $n_{O}$, por lo que la ecuación de ingreso per cápita familiar puede reescribirse como:

$$
Y_{p c}=\frac{n_{A}}{n}\left[\frac{n_{O}}{n_{A}}\left(\frac{1}{n_{O}} \sum_{i \in A}^{n} y_{i}^{L}\right) \sum_{i \in A}^{n} y_{i}^{L}+\frac{1}{n_{A}} \sum_{i \in A}^{n} y_{i}^{N L}\right]
$$

donde $n_{O}$ es la cantidad de adultos empleados del hogar.

Por lo tanto, sea $\vartheta$ cualquier medida de pobreza, la misma va a depender del ingreso per cápita familiar y con éste, de todos los factores mencionados en la ecuación (3.10). Esta medida será función entonces, de la función de densidad acumulada $F($.$) , que a la vez$ depende de cada uno de esos factores:

$$
\vartheta=\varphi\left(F\left(Y_{p c}\left(n, \frac{n_{A}}{n}, \frac{n_{O}}{n_{A}}, y_{P O}^{L}, y_{P A}^{N L}\right)\right)\right)
$$

Dado que las distribuciones del ingreso per cápita para el período $t$ y $t^{\prime}$ son conocidas, el método consiste en generar una distribución contrafáctica sustituyendo el valor observado de un determinante de la ecuación (3.11) en $t$ por el correspondiente a $t^{\prime}$, de a uno por vez. Para cada distribución contrafáctica obtenida, es posible calcular un índice de 
pobreza, que es el que hubiese prevalecido si un determinante hubiese tomado el valor del otro período. Luego, la contribución de un componente al cambio en la pobreza es la diferencia entre este índice y el calculado en base a la distribución real.

Azevedo, Nguyen y Sanfelice (2012) construyen las distribuciones contrafácticas ordenando en primer lugar los hogares por su ingreso per cápita familiar y calculando cuantiles del mismo. El promedio de cada característica para el primer cuantil en el período $t$ es reemplazado por el promedio del primer cuantil en el período $t^{\prime}$. Este procedimiento se repite para cada cuantil de la distribución, hasta reemplazarla en su totalidad.

La ecuación (3.10) en este trabajo está definida por la suma de los ingresos per cápita del hogar en concepto de salarios, ingresos de patrones, de cuentapropistas, jubilaciones, ingresos de capital, transferencias privadas, transferencias estatales y otros ingresos de manera que puede ser escrita como ${ }^{6}$ :

$$
\begin{aligned}
y_{p c}= & y_{p c}^{a s a l}+y_{p c}^{\text {patro }}+y_{p c}^{\text {ctapr }}+y_{p c}^{j u b i}+ \\
& +y_{p c}^{\text {cap }}+y_{p c}^{\text {transf }}+y_{p c}^{\text {transf }}+y_{p c}^{\text {otros }}
\end{aligned}
$$

La sustitución de los distintos componentes del ingreso per cápita familiar se realiza de a uno por vez y el impacto de los cambios de cada variable es calculado como la diferencia entre los contrafácticos acumulados para un posible sendero de cambio. Por ejemplo, el resultado de cambiar el promedio de los ingresos salariales per cápita de cada cuantil en $t$ por el valor correspondiente al de $t^{\prime}$ es una distribución contrafáctica con la que se calculará un índice de pobreza $\vartheta_{1}$. La diferencia entre este índice y el índice calculado en base a la distribución real $\left(\vartheta_{0}\right)$ será el efecto del cambio en los salarios sobre el cambio en la pobreza. Luego, al cambio en los salarios se le suma el cambio en los ingresos de patrones, obteniendo una nueva distribución contrafáctica. De esta forma, la diferencia entre el índice que resulte de esta distribución $\vartheta_{2}$, y el índice obtenido en la sustitución anterior, $\vartheta_{1}$, será la contribución del cambio en los ingresos patronales al cambio en la pobreza. El ejercicio se realiza para todos los componentes de la ecuación (3.11), obteniendo así los efectos marginales de cada determinante. Es importante notar que este

\footnotetext{
${ }^{6}$ La fuente "otros ingresos" está conformada por ingresos del hogar que no pueden ser clasificados dentro de las otras categorías. Incluye la renta implícita de la vivienda propia (en el caso de propietarios), ingresos por otras ocupaciones (por ejemplo deudas/retroactivos por ocupaciones anteriores en el mes de referencia) y otros ingresos, como limosnas o juegos de azar.
} 
mismo ejemplo se podría haber dado sustituyendo primero los ingresos por transferencias, o jubilaciones, por lo que los efectos podrían ser distintos de acuerdo al sendero de cambio que se elija, lo que es conocido como el problema de path dependence. La contribución principal del trabajo de Azevedo, Nguyen y Sanfelice (2012) es aplicar el método de Shapley-Shorrocks, que consiste en realizar el ejercicio para todos los senderos de cambio posibles y promediar el efecto. Este método, desarrollado en el ámbito de teoría de juegos, implica 8! senderos de cambio posibles (dado que el ingreso per cápita familiar se descompone en 8 determinantes), por lo que el resultado obtenido de aplicar esta metodología de descomposición será el promedio de 40320 simulaciones.

\subsection{Descomposición de Bourguignon, Ferreira y Lustig (2005)}

La tercera y última metodología de descomposición, propuesta por Bourguignon, Ferreira y Lustig (2005) y aplicada por Gasparini et al. (2005) al caso del gran Buenos Aires para descomponer cambios en desigualdad, permite medir la relevancia de distintos factores que podrían haber conducido el cambio de la pobreza, más allá de la evolución de las fuentes de ingreso. Se empleará esta metodología para determinar cuánto del cambio en la pobreza en el período analizado se asocia con cambios en características personales de los trabajadores, cuánto con cambios en los retornos a esas características y cuánto a variaciones en factores no observables y sus retornos.

Los cambios en estos factores afectan el salario horario de los trabajadores o la cantidad de horas que dedican al mercado laboral, modificando el ingreso per cápita familiar y repercutiendo así en la pobreza.

\subsubsection{Estrategia empírica.}

El ingreso total del individuo $i$ en el momento $t$ puede escribirse como la suma de los ingresos laborales $Y_{i t}^{L}$ y los ingresos no laborales $Y_{i t}^{N L}$ :

$$
Y_{i t}=Y_{i t}^{L}+Y_{i t}^{N L}
$$

A su vez, mientras los ingresos no laborales son considerados exógenos en este ejercicio, los ingresos laborales surgen del producto del salario horario $w_{i t} \mathrm{y}$ de la cantidad de horas trabajadas semanalmente $L_{i t}$ : 


$$
Y_{i t}^{L}=w_{i t} \cdot L_{i t}
$$

La ecuación (3.13) depende a su vez de características observables $X_{i t}$ que afectan tanto el salario como el empleo, de un vector de características inobservables $\varepsilon_{i t}$ y un vector de parámetros $\beta_{t}$ (que determina el salario horario) y otro $\lambda_{t}$ (que afecta los resultados de empleo):

$$
Y_{i t}^{L}=F\left(X_{i t}, \varepsilon_{i t}, \beta_{t}, \lambda_{t}\right)
$$

La ecuación (3.14) define los determinantes del ingreso laboral del individuo $i$ en el momento $t$. Sin embargo, es más relevante desde un punto de vista social analizar la distribución del ingreso per cápita familiar, dado que la utilidad de una persona depende no solo de los ingresos propios si no del ingreso del hogar y de la composición demográfica (Gasparini et al,, 2005). Por lo tanto, la variable de ingreso a estudiar en este ejercicio es el ingreso per cápita familiar, definido como:

$$
y_{i t}=\frac{1}{N_{h}} \sum_{i \epsilon h}\left(F\left(X_{i t}, \varepsilon_{i t}, \beta_{t}, \lambda_{t}\right)+Y_{i t}^{N L}\right) \quad \forall i \epsilon h
$$

donde el ingreso per cápita familiar del individuo $i$ en el momento $t$ es igual a la suma de los ingresos laborales, que dependen de ciertos factores descritos en la ecuación (3.14) y que serán objeto de la simulación, y los no laborales, dividido la cantidad de miembros del hogar.

De manera similar a la metodología anterior, se puede simular el ingreso laboral sustituyendo los argumentos de la ecuación (3.14). Sea $k$ un parámetro cualquiera de esa ecuación, es posible simular el ingreso laboral que el individuo $i$ hubiese obtenido en el momento $t$, al sustituir el valor de $k$ por el correspondiente en $t^{\prime}$, manteniendo el resto de los determinantes constantes. Dado que reemplazar los parámetros de $t^{\prime}$ en los datos de $t$ arroja resultados diferentes al hacerlo al revés, se calculan las distribuciones contrafácticas de una y otra forma y se computa el promedio de ambas.

De este modo, puede obtenerse una distribución del ingreso per cápita familiar observada, $D_{t}$ :

$$
D_{t}=\left\{Y_{1 t}, \ldots, Y_{N t}\right\}
$$

y una simulada, $D_{t k}$ :

$$
D_{t k}=\left\{Y_{1 t}\left(k_{t^{\prime}}\right), \ldots, Y_{N t}\left(k_{t^{\prime}}\right)\right\}
$$


Luego, el impacto marginal del cambio en el parámetro $k$ sobre la pobreza surge de comparar un indicador distributivo $I(D)$ calculado sobre la distribución observada y la simulada:

$$
I\left(D_{t k}\right)-I\left(D_{t}\right)
$$

\subsubsection{Estrategia de estimación}

Para simular los ingresos laborales, el modelo cuenta con una ecuación de forma reducida para los salarios horarios $w_{i t} \mathrm{y}$ una para la cantidad de horas trabajadas semanalmente $L_{i t}$ :

$$
\begin{gathered}
w_{i t}^{*}=X_{i t}^{w} \beta_{t}+\varepsilon_{i t}^{w} \\
L_{i t}^{*}=X_{i t}^{L} \lambda_{t}+\varepsilon_{i t}^{L}
\end{gathered}
$$

$\operatorname{con}\left(\varepsilon_{i t}^{w}, \varepsilon_{i t}^{L}\right) \sim N\left(0,0, \sigma_{w}, \sigma_{L}, \rho\right)$. Además,

$$
\begin{array}{ll}
w_{i t}=w_{i t}^{*} & \text { si } L_{i t}^{*}>0 \\
w_{i t}=0 & \text { si } L_{i t}^{*} \leq 0 \\
L_{i t}=L_{i t}^{*} & \text { si } L_{i t}^{*}>0 \\
L_{i t}=0 & \text { si } L_{i t}^{*} \leq 0
\end{array}
$$

donde $w_{i t} \mathrm{y} L_{i t}$ representan el salario horario y las horas trabajadas del individuo $i$ en el momento $t$ que se observa en los datos. Por su parte, $w_{i t}^{*}$ y $L_{i t}^{*}$ son variables latentes, dado que los salarios y las horas trabajadas sólo se observan para aquellas personas que participan en el mercado laboral. Los vectores $X_{i t}^{w}$ y $X_{i t}^{L}$ contienen características observables de los trabajadores que afectan al salario horario y a las horas trabajadas, respectivamente. De forma similar, los vectores $\beta_{t}$ y $\lambda_{t}$ contienen los coeficientes respectivos de cada característica en $X_{i t}^{w}$ y $X_{i t}^{L}$. Además, ambas ecuaciones están afectadas por una serie de factores inobservables $\varepsilon_{i t}^{w}$ y $\varepsilon_{i t}^{L}$, que pueden ser características de los individuos o bien, los retornos de las mismas. 
Dado que los coeficientes estimados de la ecuación (3.19) sufren de sesgo de selección debido a que sólo se observa el retorno a las características de personas que trabajan, los salarios horarios se estiman mediante el método de Heckman en dos etapas. Este método consiste en calcular, en una primera etapa la probabilidad de tener trabajo, por lo que la ecuación de selección coincide con la ecuación de horas trabajadas y luego, en una segunda etapa, los coeficientes de una ecuación de Mincer corrigiendo por el sesgo de selección ${ }^{7}$. La ecuación de horas trabajadas, por otra parte, se estima mediante un modelo Tobit de datos censurados.

El interés por estimar estas dos ecuaciones radica en el hecho de que, sustituyendo el valor en $t$ de un determinante $k$ por el valor de este en $t^{\prime}$, se puede obtener el efecto parcial que ese cambio tuvo sobre la pobreza. Este determinante $k$, recordando la ecuación (3.14), puede estar reflejando cambios en las dotaciones (como niveles educativos), en sus pagos (como retornos a la educación) o bien cambios en características inobservables y sus retornos (como la habilidad).

Los ingresos laborales que se simulan con el cambio de cada determinante $k$, se calculan sobre una muestra conformada por personas de entre 15 y 65 años, con respuestas válidas. Los restantes ingresos del hogar (ingresos de capital, de transferencias, entre otros) se mantienen inalterados, al igual que los ingresos del resto de los trabajadores de la muestra que no cumplen con la condición etaria. Por último, siguiendo a Gasparini et al. (2005), dado que las estimaciones de las ecuaciones (3.19) y (3.20) pueden diferir de acuerdo con el rol del trabajador en el hogar, las estimaciones de los parámetros distinguen jefes, cónyuges y otros miembros del hogar.

Para intentar entender los cambios en la pobreza, en esta sección se realizan 6 simulaciones $^{8}$. La primera de ellas (simulación de salarios) consiste en evaluar que hubiese sucedido con la pobreza en $t$ si todos los parámetros que determinan el salario horario de los trabajadores hubiesen sido los del momento $t^{\prime}$ (en este ejercicio el parámetro $k$ es el vector $\beta$, que incluye a la constante, $\beta^{0}$ ). Con el objetivo de aislar ciertos factores de interés en la literatura, dentro de este cambio se simulan por separado el efecto del cambio en los retornos a la educación y en la brecha de género. En el primer caso, la educación en el modelo está definida por un conjunto de variables dummies que

\footnotetext{
${ }^{7}$ La ecuación de selección del modelo tiene como variables independientes a los regresores de la ecuación de horas trabajadas (ecuación 3.20) y como variable dependiente una dummy que vale 1 cuando el individuo trabaja (percibe ingresos laborales positivos) y 0 cuando no lo hace.

${ }^{8}$ Las simulaciones se realizan de a una por vez, ceteris paribus.
} 
indican el máximo nivel educativo alcanzado por el individuo: primaria completa, secundaria incompleta, secundaria completa, superior incompleto y superior completo ${ }^{9}$. El efecto del cambio en los retornos a la educación consiste en sustituir de forma conjunta todos los coeficientes que acompañan a estas variables dummies en $t$ por los coeficientes de esta estimación en $t^{\prime}\left(k=\beta^{\text {pric }} ; \beta^{\text {seci }} ; \beta^{\text {secc }} ; \beta^{\text {supi }} ; \beta^{\text {supc }}\right)$. De esta forma, cada trabajador en $t$ recibiría el pago que le correspondería a uno con iguales características en $t^{\prime}$. Finalmente, la brecha salarial entre hombres y mujeres de un período a otro se obtiene al sustituir la diferencia esperada en los pagos entre hombres y mujeres entre períodos $\left(k=\beta^{\text {hombre }}\right)^{10}$.

Por otra parte, las características inobservables que afectan a los salarios son modeladas como los errores de la regresión (3.19) $\left(k=\varepsilon_{i t}^{w}\right)$. Con el objetivo de simular el efecto de cambios en estos factores inobservables entre $t$ y $t^{\prime}$ en la pobreza, los residuos del año $t$ son reescalados por el ratio $\sigma_{t^{\prime}} / \sigma_{t}$, donde $\sigma$ es el desvío estándar estimado en la ecuación de salarios. Los coeficientes $\beta$ estimados de los trabajadores en $t$, por su parte, se mantienen fijos.

Para evaluar la relevancia de los cambios en el empleo sobre la pobreza, se realizan dos simulaciones, que implican la sustitución del vector de coeficientes estimados de la ecuación Tobit de horas trabajadas $(k=\lambda)$. En la simulación de las horas trabajadas, se sustituye el vector de coeficientes $\lambda$ en $t$ por el de $t^{\prime}$ para todas aquellas personas que trabajan, manteniendo los salarios base. En esta simulación no hay posibilidad de cambios en el estatus laboral, por lo que aquellas personas con horas trabajadas iguales a cero no pueden incorporarse al mercado laboral, mientras que aquellas que sí lo hacían en el escenario base no pueden dejar de hacerlo en el simulado. En la segunda simulación en cambio, al intercambiar los coeficientes $\lambda$, podría suceder que personas que en el escenario base no trabajan $\left(L_{i t}=0\right)$ sí quieran hacerlo en el simulado. Estas personas necesitarán salarios y horas simuladas que resultarán del producto de sus características con los coeficientes estimados (los $\lambda$ de $t^{\prime}$ y $\operatorname{los} \beta$ de $t$ ). Para estas personas, resta definir qué errores les corresponden para las ecuaciones (3.19) y (3.20), errores que deben ser consistentes con las decisiones de no trabajar en el escenario base. Una posibilidad es utilizar los parámetros estimados $\widehat{\sigma_{W}}, \widehat{\sigma_{L}} y \hat{\rho}$ para generar aleatoriamente pares de errores

\footnotetext{
${ }^{9}$ La categoría base en esta especificación es primaria incompleta.

${ }^{10}$ En una regresión del salario horario, el coeficiente que acompaña a la variable dummy hombre representa cuánto más (o menos) gana en promedio un hombre respecto a una mujer, con el resto de las características constantes (es decir, misma educación, misma edad, etc)
} 
a partir de un muestreo de una distribución normal bivariada, implícita en el modelo de Heckman. En el caso de que los residuos así generados no resultaran consistentes con la decisión original de no trabajar, se realizaría nuevamente el muestreo de errores para ese individuo, hasta que fuese coherente con su comportamiento observado (Gasparini et al., 2005; Parada, 2014). La alternativa que se sigue en este trabajo, emula el trabajo de Gasparini, Alejo y Parada (2016). Los autores proponen, dado el costo computacional de la opción anterior, usar el método de muestreo de la transformación inversa, compatible con los supuestos estadísticos de generación de datos del modelo econométrico. De este modo, puede obtenerse un par de errores $\varepsilon_{i t}^{w}$ y $\varepsilon_{i t}^{L}$ consistentes con la decisión de no trabajar, sin la necesidad de tener que iterar varias veces hasta conseguirlo.

Finalmente, las últimas dos simulaciones corresponden a cambios en las características de los individuos: la educación $\left(k=X^{e d u}\right)$ y las decisiones de fecundidad $\left(k=X^{f e c}\right)$. Para la primera, se simulan los salarios y las horas trabajadas para los trabajadores de $t$, si la estructura educativa fuera la correspondiente a $t^{\prime}$ pero los parámetros $\beta, \lambda$ y los errores, $\varepsilon_{i t}^{w}$ y $\varepsilon_{i t}^{L}$ se mantuviesen constantes. El cambio en la estructura educativa se hace de la siguiente forma: se definen 12 grupos resultantes de la combinación de 6 grupos etarios y el género del trabajador. Posteriormente se calcula el porcentaje de trabajadores entre 15 y 65 años en cada categoría en $t^{\prime}$ para luego reemplazarlos en $t$.

Siguiendo a Badaracco (2014), las decisiones de fertilidad afectan al ingreso per cápita familiar por tres canales ${ }^{11}$. El primero de estos canales se corresponde al efecto del cambio en las decisiones de fecundidad a través del denominador de la ecuación (3.15). El segundo es el efecto tamaño horas, que hace referencia al efecto a través de las horas de trabajo. Por último, el efecto parámetro muestra la contribución del cambio en el parámetro $\lambda^{\text {hijos }}$ sobre el ingreso laboral. En este ejercicio, se simula el cambio en la cantidad de hijos de un hogar teniendo en cuenta el efecto conjunto de estos tres canales. De forma similar a la simulación del cambio en la estructura educativa, el cambio en la cantidad de hijos por hogar se hace por grupos. Estos grupos están formados por la combinación de quintiles de ingreso del jefe y cónyuge y la edad del jefe del hogar ${ }^{12}$. Luego, se calcula la cantidad de hijos que en promedio tiene un grupo determinado en $t^{\prime}$

\footnotetext{
${ }^{11}$ En su trabajo, Badaracco (2014) especifica seis efectos: tamaño directo, tamaño horas, tamaño ingreso no laboral, tamaño total, parámetros y efecto total.

12 Para la formación de grupos, se tuvieron en cuenta tres divisiones de edad del jefe de hogar ([15-25), $[25,45)$ y $[45,+))$ junto con 5 quintiles de ingreso del jefe y cónyuge, formando 15 grupos en total.
} 
y se lo reemplaza en $t$, para determinar a continuación cuantas horas desearían trabajar los ocupados del período base, con la nueva estructura de hijos.

\section{Resultados}

Esta sección resume los resultados obtenidos de aplicar las metodologías detalladas en la sección 3 a los datos de Argentina, en el período 2003-2015.

\subsection{Efectos crecimiento y redistribución}

En una aproximación simple de los determinantes de los cambios en la pobreza, este tipo de descomposición permite determinar en qué magnitud la caída en la pobreza experimentada por Argentina responde al crecimiento económico y hasta qué punto este efecto se ve reforzado o no por el cambio en la forma de la distribución.

El comportamiento de ambas variables puede verse en la Figura 4.1. El eje izquierdo mide el ingreso per cápita familiar, como proxy de crecimiento económico, en pesos constantes de 2015. El eje derecho muestra el coeficiente de Gini como indicador de desigualdad. En la evolución de ambas variables es posible ver un comportamiento similar al presentado por la pobreza. En una primera etapa, el ritmo de cambio es considerable. El ingreso per cápita familiar pasó de $\$ 3050$ en 2003 a $\$ 4259$ en 2007, lo que implica un aumento del 40\%. La desigualdad por su parte presentó una caída de 5 puntos. Entre 2007 y 2011, si bien el ingreso creció y la desigualdad cayó, ambas variables lo hicieron a un ritmo más moderado (12\% y 3.4 puntos respectivamente). Finalmente y al igual que la pobreza, tanto la desigualdad como el crecimiento parecen haberse estancado durante el tramo 2011-2015. El coeficiente de Gini pasó de 0.42 a 0.41 entre 2011 y 2015, lo que representa una caída de 1.4 puntos y el ingreso de hecho, cayó, en aproximadamente un $2 \%$. 
Figura 4.1. Crecimiento y desigualdad.

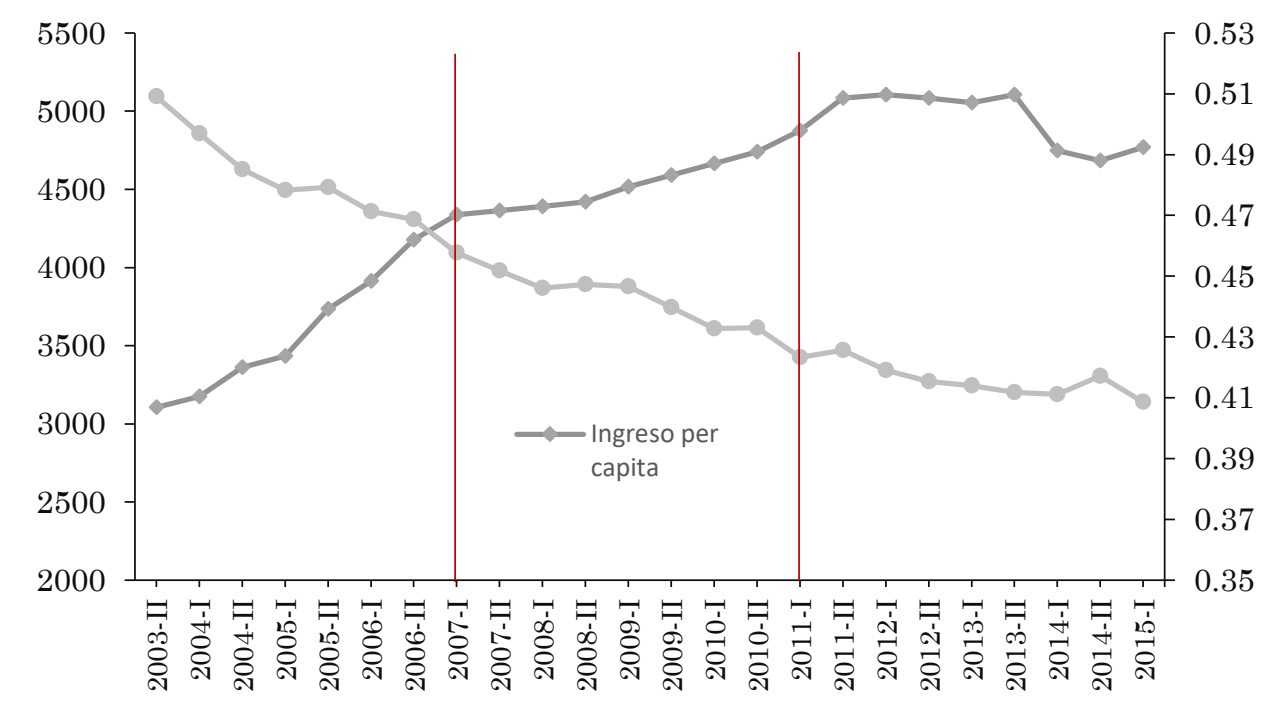

Nota: Ingreso per cápita familiar a pesos constantes de 2015. Coeficiente de Gini basado en ingreso per cápita familiar.

Fuente: Elaboración propia en base a datos de la EPHC.

La Tabla 4.1 muestra la descomposición en el cambio en la pobreza en Argentina para los tres indicadores usuales de pobreza: tasa, brecha y severidad. La primera columna muestra la descomposición de la tasa de incidencia a 4 dólares PPA. Para el período completo, el efecto del crecimiento económico y del cambio en la desigualdad es parejo: de los 23 puntos de caída, el primero fue responsable del 53\%, mientras que el segundo lo fue del $47 \%$.

Al mirar por tramos, la caída en la pobreza entre 2003 y 2007 estuvo asociada fundamentalmente al aumento generalizado de los ingresos en esa etapa: el efecto crecimiento da cuenta del $65 \%$ de la reducción de la tasa de incidencia en la pobreza. De forma contraria, el efecto redistribución es el que predomina en el período siguiente, siendo responsable de aproximadamente el 60\% de la caída. En el último período, 20112015, la pobreza sufrió un cambio muy pequeño pero negativo gracias al efecto redistribución, ya que el efecto crecimiento estuvo asociado a un leve aumento de la pobreza.

Los mismos patrones se repiten en el caso de la brecha y la severidad de la pobreza. Para todo el período, tanto el efecto crecimiento como redistribución parecen tener un impacto parecido, aunque el efecto redistribución representa levemente un mayor impacto. En la primera etapa (2003-2007) el aumento de los ingresos es el mayor responsable de la caída en la brecha y severidad de la pobreza, efecto que se revierte en la segunda etapa, en 
donde la caída de la pobreza de desacelera. Finalmente, el cambio en el componente redistributivo es el que provoca una leve caída de los indicadores de pobreza en el tramo 2011-2015, ya que el efecto crecimiento atenúa la reducción observada.

Tabla 4.1. Descomposición efecto crecimiento y redistribución.

\begin{tabular}{|c|c|c|c|c|c|c|}
\hline & \multicolumn{3}{|c|}{4 usd } & \multicolumn{3}{|c|}{2 usd } \\
\hline & Tasa & Brecha & Profundidad & Tasa & Brecha & Profundidad \\
\hline \multicolumn{7}{|l|}{ 2003-2015 } \\
\hline Efecto Crecimiento & -12.3 & -5.3 & -3.0 & -7.2 & -2.5 & -1.3 \\
\hline Efecto Redistribución & -10.8 & -6.4 & -4.3 & -8.8 & -4.2 & -2.6 \\
\hline Total & -23.0 & -11.7 & -7.3 & -16.0 & -6.7 & -4.0 \\
\hline \multicolumn{7}{|l|}{ 2003-2007 } \\
\hline Efecto Crecimiento & -9.8 & -4.7 & -2.9 & -6.4 & -2.6 & -1.5 \\
\hline Efecto Redistribución & -5.4 & -2.8 & -1.7 & -3.5 & -1.6 & -1.0 \\
\hline Total & -15.1 & -7.5 & -4.6 & -9.9 & -4.1 & -2.4 \\
\hline \multicolumn{7}{|l|}{$2007-2011$} \\
\hline Efecto Crecimiento & -2.6 & -1.0 & -0.6 & -1.3 & -0.5 & -0.2 \\
\hline Efecto Redistribución & -3.8 & -2.4 & -1.7 & -3.4 & -1.7 & -1.1 \\
\hline Total & -6.5 & -3.4 & -2.2 & -4.7 & -2.1 & -1.3 \\
\hline \multicolumn{7}{|l|}{ 2011-2015 } \\
\hline Efecto Crecimiento & 0.4 & 0.2 & 0.1 & 0.1 & 0.1 & 0.0 \\
\hline Efecto Redistribución & -1.9 & -1.0 & -0.6 & -1.5 & -0.5 & -0.2 \\
\hline Total & -1.4 & -0.8 & -0.5 & -1.4 & -0.4 & -0.2 \\
\hline
\end{tabular}

Nota: Valor promedio de los cambios simulados en la tasa de pobreza en cada período, calculada en base al ingreso per cápita familiar. Línea de 4 dólares por día por persona a PPA.

Fuente: Elaboración propia en base a la EPHC.

Al descomponer el cambio en la tasa de pobreza con esta metodología para una línea de pobreza más baja, como la de 2 dólares por día, los resultados obtenidos son muy similares a los obtenidos para la línea de pobreza de 4 dólares, como puede verse en las tres últimas columnas de la Tabla 4.1. La única diferencia se encuentra en el análisis del período completo, en donde el efecto redistribución es mayor que el efecto crecimiento. De todas formas, al igual que con la línea de 4 dólares, la diferencia entre ambos componentes es pequeña para la tasa de pobreza. Esta diferencia crece a medida que el parámetro $\alpha$ del indicador FGT lo hace.

\subsection{Descomposición por fuentes de ingresos}

En un análisis un poco más profundo, la metodología de Acevedo et al. (2012) permite descomponer el cambio en la pobreza por fuentes de ingresos. Como se explicó en la sección anterior, el ingreso per cápita familiar puede ser expresado como la suma per cápita de los ingresos del hogar en concepto de salarios, ingresos de patrones, de 
cuentapropistas, jubilaciones, ingresos de capital, transferencias privadas, transferencias estatales y otros ingresos.

La Tabla 4.2 muestra la evolución de los componentes del ingreso en valores constantes de 2015 para los años de análisis. Durante la primera etapa, los salarios parecen ser la fuente de ingresos con mayor cambio positivo (43.7\%), al pasar en promedio de $\$ 4588$ en 2003 a \$6594 en 2007. El resto de los ingresos laborales, cuentapropistas y patronales, experimentaron aumentos similares, de aproximadamente $33 \%$ cada uno, mientras que los ingresos de capital cayeron, alrededor del 40\%. Las jubilaciones, cuyo poder de compra se duplicó a partir del año 2003 y alcanzó el pico máximo en la moratoria de 2007 (su cobertura aumentó un 23\%), crecieron alrededor del 13\%. En la misma dirección las transferencias privadas aumentaron un $21 \%$, mientras que las transferencias estatales cayeron, tanto en monto como en cobertura: $18.6 \%$ y $45 \%$ respectivamente.

El segundo tramo, de 2007 a 2011, presenta en general una evolución parecida a los años anteriores, aunque de forma más atenuada. Los ingresos patronales y las jubilaciones son la excepción, ya que sufrieron una caída del $16.6 \%$ en el primer caso y $1.6 \%$ en el segundo. A pesar de la disminución experimentada en el monto promedio de las mismas, su cobertura se amplió, alcanzando a 3.4 millones de personas. De forma similar, el monto promedio de las transferencias estatales continuó su caída, más moderada, al tiempo que alcanzó a un mayor número de personas, en el marco de la implementación de la Asignación Universal por Hijo (AUH).

Finalmente, el último período estuvo caracterizado por una caída en todas las fuentes de ingreso, con excepción de las jubilaciones (13.1\%), las transferencias estatales (8.3\%), y otros ingresos del hogar (3.9\%). 
Tabla 4.2. Evolución de las fuentes de ingreso.

\begin{tabular}{lcccccccc}
\hline \hline & \multicolumn{4}{c}{ Promedio } & \multicolumn{5}{c}{ Cambio (\%) } \\
\cline { 2 - 9 } & $2003-\mathrm{II}$ & $2007-\mathrm{I}$ & $2011-\mathrm{I}$ & $2015-\mathrm{I}$ & $2003-2007$ & $2007-2011$ & $2011-2015$ & $2003-2015$ \\
\hline Salario & 4588 & 6594 & 7412 & 7302 & 43.7 & 12.4 & -1.5 & 59.1 \\
Ingresos patronales & 10454 & 13810 & 11516 & 9718 & 32.1 & -16.6 & -15.6 & -7.0 \\
Ingresos cuenta propista & 3997 & 5349 & 5535 & 5334 & 33.8 & 3.5 & -3.6 & 33.5 \\
Jubilaciones & & & & & & & & \\
$\quad$ Monto promedio & 3691 & 4177 & 4110 & 4647 & 13.2 & -1.6 & 13.1 & 25.9 \\
$\quad$ Cobertura & 2.11 & 2.60 & 3.40 & 3.71 & 23.0 & 30.8 & 9.0 & 75.3 \\
Ingresos de capitales & 10104 & 5704 & 5666 & 5053 & -43.6 & -0.7 & -10.8 & -50.0 \\
Ingreso por transferencias p. & 2376 & 2872 & 3074 & 2669 & 20.9 & 7.0 & -13.2 & 12.3 \\
Ingreso por transferencias e. & & & & & & & & -14.5 \\
$\quad$ Monto promedio & 1314 & 1069 & 1037 & 1123 & -18.6 & -3.1 & 8.3 & 52.6 \\
$\quad$ Cobertura & 0.86 & 0.47 & 1.14 & 1.31 & -45.0 & 142.9 & 14.3 & 3.9 \\
Otros ingresos & 2002 & 2268 & 2577 & 2678 & 13.3 & 13.6 & 3.9 & 33.8 \\
\hline
\end{tabular}

Nota: Valores en pesos constantes de 2015, para hogares con respuestas válidas. La cobertura de las jubilaciones y las transferencias estatales están expresadas en millones de personas.

Fuente: Elaboración propia en base a datos de la EPHC.

La Figura 4.2 muestra los resultados de la descomposición de la tasa de incidencia para una línea de 4 dólares por día (panel a) y para una de 2 dólares por día (panel b) ${ }^{13}$. Gran parte de la caída en la tasa de pobreza a 4 dólares en el primer período estuvo asociada al aumento en el ingreso de los asalariados, que contribuyó en un $71 \%$, seguido por los cuentapropistas y las jubilaciones, que aportaron aproximadamente el 9 y $10 \%$ de la reducción, en un contexto de duplicación en la jubilación mínima y en el pico de altas en las moratorias previsionales. Las transferencias estatales, por el contrario, contribuyeron al aumento de la pobreza en el período ( 0.8 puntos). Este resultado podría estar reflejando la transición producida en estos años entre el Plan Jefes y la Asignación Universal por Hijo. Este efecto se revierte en el siguiente período posiblemente por el lanzamiento de la AUH en 2009, que contribuye en un 17\% a la caída de la pobreza en el segundo tramo, en donde nuevamente es el aumento de los ingresos asalariados lo que aporta más a la reducción (51\%). Los ingresos por jubilaciones tuvieron un importante papel en este tramo, aportando un $16 \%$ de los 6.5 puntos de caída en la brecha de la pobreza. El último tramo de análisis está caracterizado por una clara desaceleración de la caída en la pobreza. De las pocas fuentes que contribuyeron a la caída de la tasa de incidencia a 4 dólares por día, los salarios fueron nuevamente los mayores responsables $(80 \%)$, seguido por las jubilaciones y los ingresos por cuentapropia (ambos 19\%).

La descomposición de la pobreza para el período completo sigue los mismos patrones. Los ingresos laborales (salariales, cuentapropistas y de empleadores) representan la

\footnotetext{
${ }^{13}$ Para más detalles, ver Tabla A.3 en el anexo.
} 
fuente que mayor peso ha tenido en la reducción de la pobreza. Estos resultados van en línea con lo encontrado por Inchauste et al (2014) para Argentina, en el período 20002010. Los resultados de la descomposición para una línea de pobreza de 2 dólares son muy similares, como puede observarse en el panel $b$.

Figura 4.2. Descomposición por fuentes de ingreso.

(a)

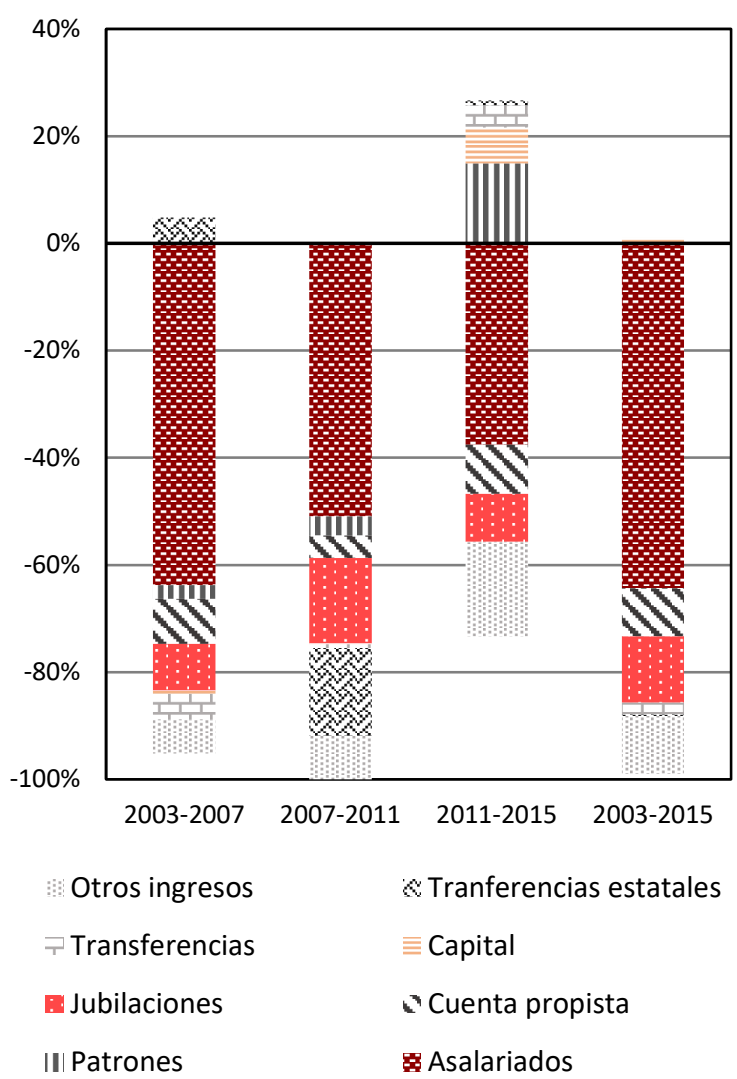

(b)

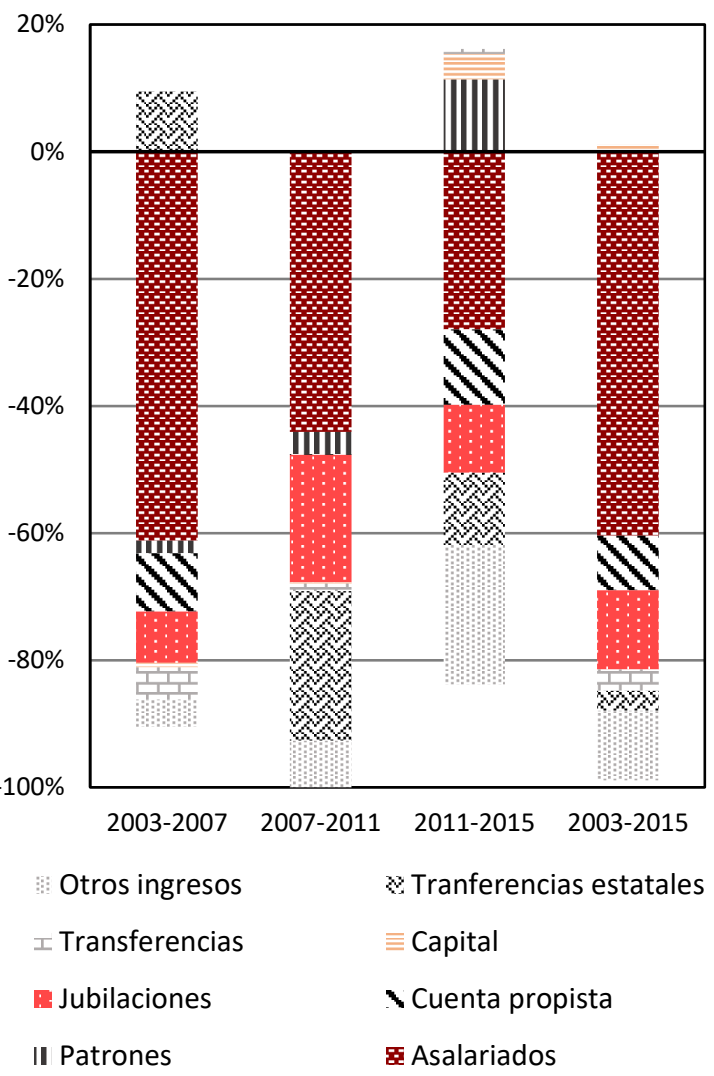

Nota: Descomposición de Acevedo et al (2012) de la tasa de incidencia de la pobreza, calculada en base al ingreso per cápita familiar. Panel a: línea de 4 USD por día. Panel b: línea de 2 USD por día. Fuente: Elaboración propia en base a datos de la EPHC.

Los resultados de la descomposición son consistentes al pasar de la tasa a la brecha de pobreza $^{14}$. La importancia del aumento en los ingresos de los asalariados se mantiene también para este indicador, como muestra la Figura 4.3. Las transferencias estatales cobran un mayor peso en la reducción de la brecha de pobreza respecto a la tasa, indicando que, si bien el monto asignado a las familias informales con hijos no alcanza para sacar a muchos hogares de la pobreza, sí los acerca más hacia el umbral. Si bien una pequeña parte de la reducción en la tasa y brecha de la pobreza se ha debido al cambio en otros

\footnotetext{
${ }^{14}$ También lo son al mirar la severidad de la pobreza. Ver Tabla A.3 en el Anexo.
} 
ingresos, es en la segunda medida de pobreza en dónde adquiere mayor relevancia, sobre todo entre los años 2003-2007 y 2007-2011.

Figura 4.3. Descomposición por fuentes de ingreso.

(a)

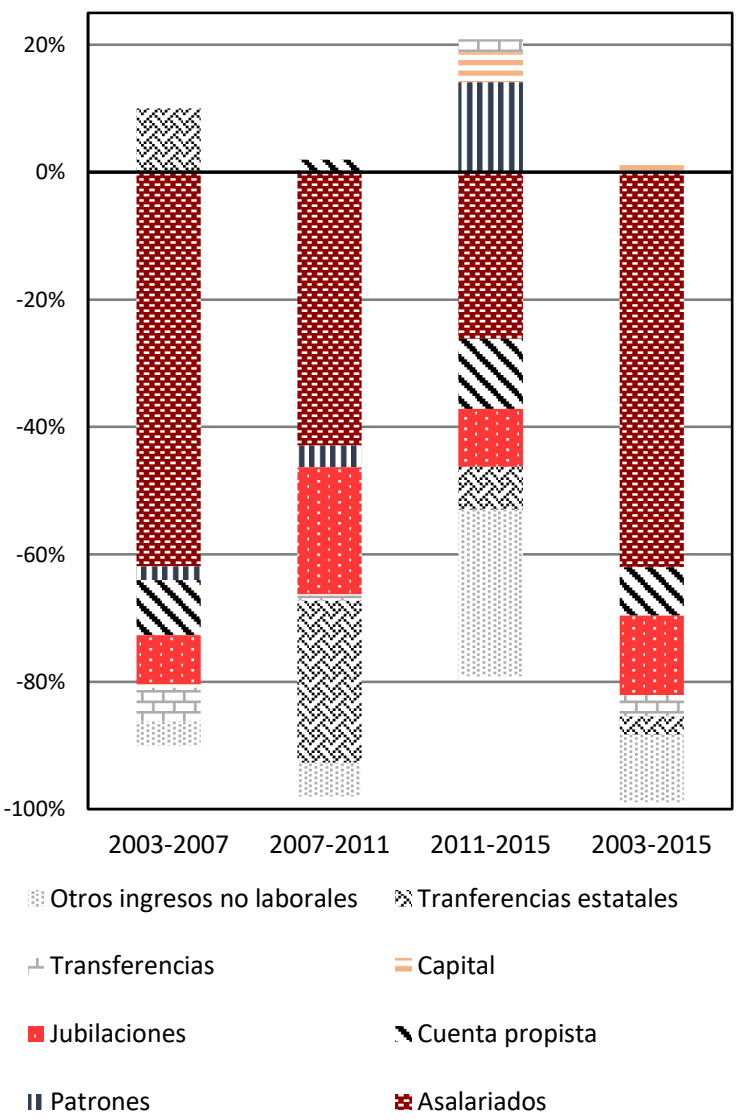

Brecha de pobreza

(b)

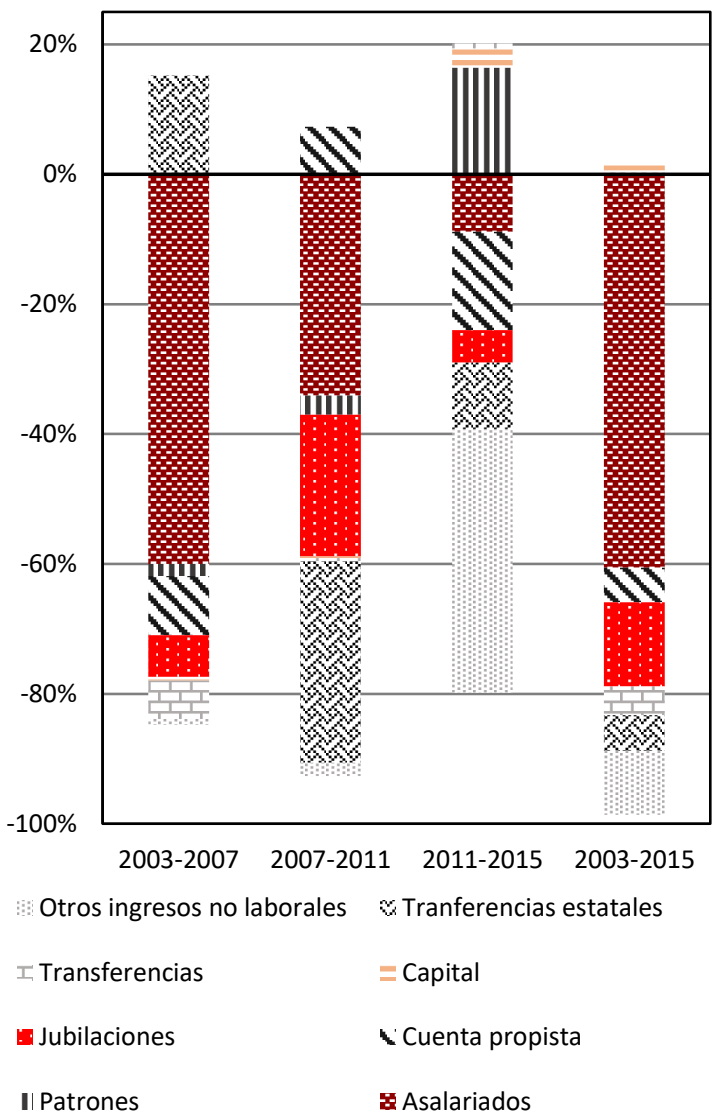

Nota: Descomposición de Acevedo et al (2012) de la brecha de la pobreza, calculada en base al ingreso per cápita familiar. Panel a: línea de 4 USD por día. Panel b: línea de 2 USD por día.

Fuente: Elaboración propia en base a datos de la EPHC.

\subsection{Descomposición de Bourguignon, Ferreira y Lustig (2005)}

El método de descomposición desarrollado en la sección anterior señala en general a los ingresos laborales como el principal responsable de la reducción de la pobreza en Argentina para el período analizado. Sin embargo, no es posible saber mucho más acerca de las razones por las cuales los ingresos laborales aumentaron. El método propuesto por Bourguignon et al (2005) permite capturar de forma parcial el efecto de varios factores que podrían haber conducido los cambios en la pobreza.

En primer lugar, se revisará brevemente la evolución de los potenciales determinantes descritos en la sección 3 para luego analizar los efectos de estos cambios sobre la pobreza. 


\subsubsection{Salarios}

La evolución del salario horario (en pesos constantes de 2015) en Argentina se muestra en la Tabla 4.3, para cada quintil de ingreso per cápita familiar. Para el total del período, si bien todos los quintiles han experimentado aumentos en esta variable, son los más bajos los que presentan el mayor crecimiento $(65.3 \%$ y $65.7 \%$ para el quintil 1 y 2 , respectivamente)

Al mirar por períodos, en promedio los salarios han tenido un comportamiento similar a la evolución de la pobreza: una primera etapa de aumento considerable, de alrededor del $25 \%$, un período de desaceleración, del $8 \% \mathrm{y}$, finalmente, uno de estancamiento, en el que el crecimiento de los últimos cuatro años fue $0.6 \%$. A pesar de que durante la primera etapa de análisis el aumento del salario horario en promedio es homogéneo, durante las siguientes dos etapas el crecimiento fue mayor para los quintiles más bajos de ingresos.

Tabla 4.3. Salario horario por quintil de ingresos.

\begin{tabular}{lcccccccc}
\hline \hline & \multicolumn{3}{c}{ Promedio (\$2015) } & \multicolumn{4}{c}{ Cambio (\%) } \\
\cline { 2 - 9 } & 2003-II & $2007-\mathrm{I}$ & $2011-\mathrm{I}$ & $2015-\mathrm{I}$ & $2007-2003$ & $2011-2007$ & $2015-2011$ & $2015-2003$ \\
\hline Quintil 1 & 15.9 & 20.1 & 24.2 & 26.3 & 26.0 & 20.4 & 8.9 & 65.3 \\
Quintil 2 & 20.9 & 28.1 & 32.5 & 34.7 & 34.0 & 15.7 & 6.9 & 65.7 \\
Quintil 3 & 25.5 & 35.7 & 40.0 & 41.4 & 39.8 & 12.0 & 3.5 & 62.2 \\
Quintil 4 & 33.3 & 45.1 & 50.1 & 52.6 & 35.5 & 11.1 & 4.8 & 57.9 \\
Quintil 5 & 64.3 & 77.2 & 79.7 & 75.8 & 20.1 & 3.3 & -5.0 & 17.9 \\
\hline Total & 37.4 & 46.9 & 50.6 & 50.9 & 25.3 & 8.0 & 0.6 & 36.1 \\
\hline
\end{tabular}

Nota: Salario horario en todas las ocupaciones por quintil de ingreso per cápita familiar. Pesos constantes de 2015. Trabajadores de entre 15 y 65 años, con respuestas válidas.

Fuente: Elaboración propia en base a datos de la EPHC.

La Tabla 4.3, sin embargo, no es suficiente para analizar la evolución de los salarios horarios, ya que no tiene en cuenta otras características de los trabajadores, como el nivel educativo o el género del trabajador. La Figura 4.4 muestra el logaritmo del salario horario predicho para un trabajador jefe de hogar (panel a) y una trabajadora jefa de hogar (panel b), ambos estimados mediante el método de Heckman (Tabla A1 en el anexo). El salario horario aumentó en todos los períodos de interés, al menos para los primeros quintiles de ingreso per cápita familiar. Además, es interesante mencionar que este aumento no ha sido igual para todos los quintiles, sino que los trabajadores de la cola izquierda de la distribución son los más favorecidos en la evolución de esta variable. 
Figura 4.4. Logaritmo del salario horario por quintil de ingreso.

(a) Hombres

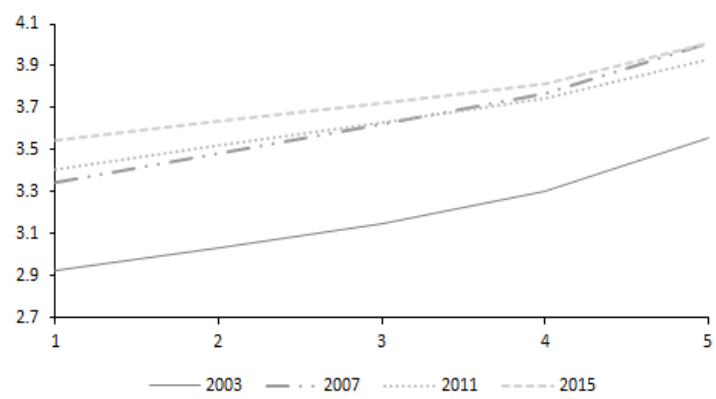

(b) Mujeres

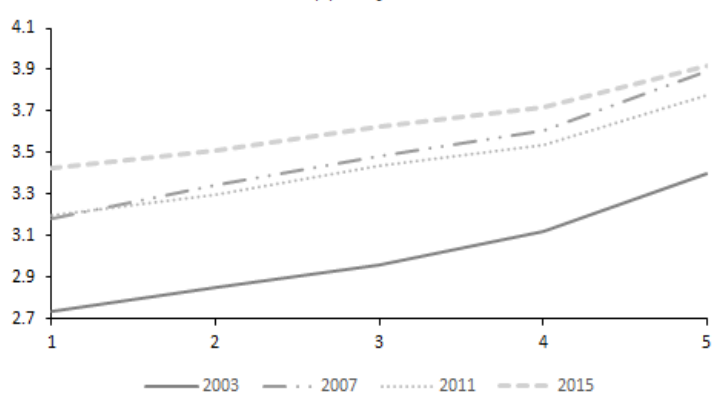

Nota: Logaritmo del salario horario predicho en todas las ocupaciones por quintil de ingreso per cápita familiar. Jefes de hogar de entre 15 y 65 años de edad, con respuestas válidas. Panel a: hombres; Panel b: mujeres

Fuente: Elaboración propia en base a datos de la EPHC.

\subsubsection{Retornos a la educación}

A pesar de la utilidad de analizar los cambios en la pobreza ante cambios en todos los parámetros de la ecuación que determina el salario horario de los trabajadores, mucha de la literatura ha prestado especial atención al parámetro que acompaña a las características educativas del trabajador, conocido como retornos a la educación. Según la teoría del capital humano, mayores niveles educativos tienden a incrementar la productividad y en consecuencia el salario horario de las personas (Mincer, 1958).

La Tabla 4.4 muestra el salario horario de los trabajadores para cada nivel educativo. El primer tramo de análisis es el que registra los mayores aumentos del salario horario, de una forma casi homogénea a través de los grupos educativos. El salario horario de los trabajadores con primaria incompleta aumentó un $27.8 \%$ de 2003 a 2007, mientras que aquellos con primaria completa y secundaria incompleta vieron sus salarios aumentados en un $26.6 \%$ y $24.7 \%$, respectivamente. Los años siguientes, si bien experimentaron aumentos en el salario horario de casi todos los grupos educativos, fueron menores.

A pesar de que la Tabla 4.4 podría sugerir una reducción de la pobreza debido al aumento de salarios de los grupos de baja educación, en especial en el primer período de análisis, no es suficiente para determinar qué ocurrió con los retornos a cada grupo. 
Tabla 4.4. Salario horario por nivel educativo.

\begin{tabular}{lcccccccc}
\hline \hline & \multicolumn{3}{c}{ Promedio (\$2015) } & \multicolumn{4}{c}{ Cambio (\%) } \\
\cline { 2 - 9 } & 2003-II & $2007-\mathrm{I}$ & $2011-\mathrm{I}$ & $2015-\mathrm{I}$ & $2007-2003$ & $2011-2007$ & $2015-2011$ & $2015-2003$ \\
\hline Primaria incompleta & 21.9 & 27.9 & 30.4 & 35.0 & 27.8 & 8.7 & 15.2 & 60.0 \\
Primaria completa & 25.8 & 32.7 & 35.6 & 38.4 & 26.6 & 8.9 & 7.8 & 48.7 \\
Secundaria incompleta & 27.0 & 33.7 & 37.4 & 38.6 & 24.7 & 11.0 & 3.1 & 42.8 \\
Secundaria completa & 33.0 & 42.8 & 46.4 & 45.7 & 29.7 & 8.4 & -1.4 & 38.5 \\
Superior incompleto & 41.7 & 51.8 & 54.6 & 56.4 & 24.1 & 5.5 & 3.3 & 35.3 \\
Superior completo & 68.3 & 81.9 & 80.6 & 76.2 & 19.9 & -1.6 & -5.5 & 11.6 \\
\hline Total & 37.4 & 46.9 & 50.6 & 50.9 & 25.3 & 8.0 & 0.6 & 36.1 \\
\hline
\end{tabular}

Nota: Salario horario en todas las ocupaciones. Pesos constantes de 2015. Trabajadores de entre 15 y 65 años de edad, con respuestas válidas.

Fuente: Elaboración propia en base a datos de la EPHC.

La Tabla A1 en el anexo muestra los resultados de las regresiones de Mincer del logaritmo del salario horario. En ellas, siguiendo a Gasparini et al. (2005), la educación es capturada a través de variables dummies que indican si el trabajador posee primaria completa, secundaria incompleta, secundaria completa, superior incompleto o superior completo. Además, también se incluyen en la regresión la edad y su cuadrado, una variable dummy de género y las correspondientes a las regiones argentinas ${ }^{15}$. La ecuación de selección del modelo agrega además el estado civil, el número de hijos, la asistencia a un establecimiento educativo, la minoría de edad (menor a 18 años) y la condición laboral del jefe y del cónyuge como determinantes de la decisión de participar o no en el mercado laboral. Las primeras cuatro columnas muestran los coeficientes estimados en cada año disponible para los jefes del hogar, las siguientes cuatro para los cónyuges y las últimas para otros miembros del hogar, todos entre 15 y 65 años.

Los retornos a la educación representan un pago que en general ha disminuido a lo largo del tiempo. Con excepción del primer subperíodo para jefes y cónyuges, los coeficientes de todos los niveles educativos han caído de un período a otro, consistente con lo observado por Lustig et al (2013) para muchos países de América Latina. Así, en 2003 un jefe de hogar con secundaria incompleta percibía en promedio un salario horario $36.5 \%$ mayor que un jefe de iguales características con primaria incompleta. Esta diferencia alcanzaba el $73.8 \%, 121.9 \%$ y $213.9 \%$ en los casos de secundaria completa, superior incompleto y superior completo. En 2015, estas brechas se redujeron a 30\%,

\footnotetext{
${ }^{15}$ La categoría base del conjunto de dummies de región es "Gran Buenos Aires".
} 
$55.1 \%, 83.9 \%$ y $139.1 \%$ respectivamente. Esta tendencia a la baja se encuentra para cualquiera de los tres roles en el hogar: jefe, cónyuge y otros miembros. ${ }^{16}$

Al mirar la Tabla A1 por tramos resulta evidente que, en general, para la primera etapa los retornos a la educación crecieron, al menos para jefes y cónyuges, y en mayor medida para los niveles bajos de educación, es decir, primaria completa y secundaria incompleta. Si bien estos coeficientes representan una brecha salarial respecto a trabajadores con primaria incompleta, teniendo en cuenta que los salarios en esta etapa aumentaron de forma generalizada para todos los grupos educativos, y que la mayor parte de los trabajadores en hogares pobres se concentra en los niveles de primaria completa y secundaria incompleta (Tabla 4.4), esta evolución de los retornos podría estar implicando reducciones en la pobreza.

Tabla 4.4. Porcentaje de individuos en situación de pobreza por nivel educativo.

\begin{tabular}{lcccc}
\hline \hline & \multicolumn{4}{c}{ Promedio } \\
\cline { 2 - 5 } & $2003-\mathrm{II}$ & $2007-\mathrm{I}$ & $2011-\mathrm{I}$ & $2015-\mathrm{I}$ \\
\hline Primaria incompleta & 16.59 & 16.49 & 14.10 & 9.33 \\
Primaria completa & 32.47 & 31.25 & 27.54 & 24.81 \\
Secundaria incompleta & 30.73 & 33.07 & 33.32 & 38.69 \\
Secundaria completa & 11.71 & 12.28 & 15.88 & 15.14 \\
Superior incompleto & 6.05 & 4.80 & 6.54 & 8.20 \\
Superior completo & 2.43 & 2.12 & 2.63 & 3.84 \\
\hline
\end{tabular}

Nota: Porcentaje de personas pertenecientes a la muestra de 15 a 65 años cuyo ingreso per cápita familiar no supera la línea de pobreza a 4 dólares diarios PPA.

Fuente: Elaboración propia en base a datos de la EPHC.

Las caídas en los retornos producidas en la segunda y tercera etapa de análisis fueron de carácter general. Sin excepción, el pago a la educación para todos en la muestra cayó, reduciendo la brecha respecto a los de primaria incompleta, con los efectos más grandes concentrados en la educación media (secundaria incompleta, secundaria completa y superior incompleto).

En resumen, la caída en los retornos a la educación en casi todos los períodos afectó a todos los grupos educativos. Al contrario de lo que pasa al descomponer indicadores de desigualdad, no resulta claro el efecto que la evolución de los retornos a la educación podría tener sobre indicadores de pobreza. En general, los salarios no condicionados

\footnotetext{
${ }^{16}$ Los retornos de primaria completa para jefes de hogar parecen ser la excepción a esta regla en el período 2003 - 2015, ya que aumentaron de 0.165 a 0.171 .
} 
vistos en la Tabla 4.3 aumentaron para todos los períodos y grupos educativos, en especial los de primaria incompleta, que constituye la categoría omitida en la regresión de salarios. Dada esta información, que los retornos de primaria completa y secundaria incompleta hayan caído implica que lo hicieron porque los pagos a estos niveles lo hicieron. Como estos grupos son los que presentan mayor porcentaje de hogares en situación de pobreza, esta evolución en los retornos pudo haber afectado de forma negativa a la evolución de la pobreza, aumentándola, durante la mayor parte del período analizado.

\subsubsection{Brecha salarial de género.}

De acuerdo con Gasparini y Marchionni (2015), el gran aumento en la participación laboral femenina se encuentra dentro de los cambios socioeconómicos más sobresalientes en América Latina en el último medio siglo. No obstante, este avance ha sido insuficiente para cerrar la brecha entre hombres y mujeres en la mayoría de las variables del mercado laboral, como salarios o empleo. Más allá de todas las implicancias sociales que este hecho implica, si se tiene en cuenta que las mujeres son menos propensas a trabajar, ganan menos que los hombres por trabajos similares, y es más probable que estén en la pobreza incluso cuando trabajan (Duflo, 2012) la reducción de la brecha de salarios entre hombres y mujeres podría tener un efecto sobre los cambios en pobreza experimentados por Argentina.

Para analizarlo, se ha incluido en la regresión de Mincer una dummy de género que vale 1 en el caso de que la observación corresponda a un hombre y 0 en caso de que no. El coeficiente de esta variable refleja cuánto más gana un hombre en promedio respecto a una mujer, ceteris paribus, por lo que se interpreta como la brecha salarial que existe en el mercado laboral.

La Tabla A1 muestra la brecha condicional entre hombres y mujeres para cada año analizado. El coeficiente de la variable hombre es positivo y significativo para jefes y otros miembros del hogar indicando que, efectivamente, los hombres ganan en promedio más que las mujeres, a igualdad de características. Así, en 2003 un trabajador hombre jefe de hogar obtenía en promedio un salario horario un $21.2 \%$ mayor que el obtenido por una mujer. En 2015 esa brecha se redujo a 15.8\%. 
De forma similar pero en menor medida, durante el primer período de análisis la brecha salarial entre hombres y mujeres se redujo aproximadamente 1 punto, llegando al $20 \%$. Para el segundo período, en cambio, se produjo un aumento en el coeficiente de la variable dummy ya que el salario horario de un trabajador masculino pasó a ser en promedio un $24.6 \%$ mayor que el de una mujer, a igualdad de condiciones. Finalmente, de 2011 a 2015 se produjo una reducción en la brecha salarial que, como se señaló, alcanzó el 15.8\%.

\subsubsection{Inobservables}

El término de error de la ecuación de salarios captura características inobservables de los individuos, como la habilidad o los contactos. Sin embargo, también captura los retornos a dichas características. Como se explicó anteriormente, el efecto del cambio en características inobservables se obtiene reescalando el término de error de la ecuación de salarios en $t$ con el ratio de desviaciones estándar entre $t^{\prime}$ y $t$.

La varianza del término de error en cada estimación (o sigma) puede verse en la Tabla A1. Tanto en el período completo como entre subperíodos, el valor de la varianza estimada ha caído: mientras en 2003 un jefe de hogar tenía un sigma estimado de 0.77, este valor era, para 2007, 0.69, 0.65 en 2011 y 0.61 para 2015. Este patrón se mantuvo para cónyuges y otros miembros del hogar.

\subsubsection{Horas trabajadas}

Las horas semanales trabajadas han experimentado una pequeña caída durante el período analizado, con excepción de los cuatro primeros años (Tabla 4.5). En efecto, mientras que entre los años 2003 y 2007 el número de horas trabajadas en el mercado laboral aumentó en promedio 0.8, entre 2007 y 2011 cayó hasta llegar al nivel del año 2003. Finalmente, en el último período esta tendencia no cambió: las horas trabajadas continuaron cayendo hasta llegar a 40.5 en promedio. 
Tabla 4.5. Horas trabajadas.

\begin{tabular}{lcccccccc}
\hline \hline & \multicolumn{4}{c}{ Promedio } & \multicolumn{4}{c}{ Cambio (\%) } \\
\cline { 2 - 8 } & $2003-\mathrm{II}$ & $2007-\mathrm{I}$ & $2011-\mathrm{I}$ & $2015-\mathrm{I}$ & $2007-2003$ & $2011-2007$ & $2015-2011$ & $2015-2003$ \\
\hline $\begin{array}{l}\text { Horas trabajadas por } \\
\text { semana }\end{array}$ & 42.0 & 42.8 & 42.1 & 40.5 & 2.0 & -1.7 & -3.8 & -3.6 \\
\hline
\end{tabular}

Nota: Cantidad de horas trabajadas por semana. Trabajadores de entre 15 y 65 años, con respuestas válidas. Fuente: Elaboración propia en base a datos de la EPHC.

La Tabla 4.5 muestra las horas trabajadas no condicionadas promedio de la muestra. La Figura 4.5 por su parte, contiene las horas predichas por quintil de ingreso, con el objetivo de vislumbrar algún comportamiento diferencial entre trabajadores de distintas partes de la distribución. En líneas generales, en todos los períodos el número de horas trabajas cayó para todos los trabajadores hombres (panel a), siendo la brecha mayor para los quintiles más altos de ingreso. La excepción se encuentra en el primer período para el primer y segundo quintil, en donde la cantidad de horas trabajadas en promedio fue mayor al año base. La evolución de las horas trabajadas para las jefas mujeres comparte en promedio la misma dinámica.

Figura 4.5. Horas trabajadas semanalmente por quintil de ingreso.
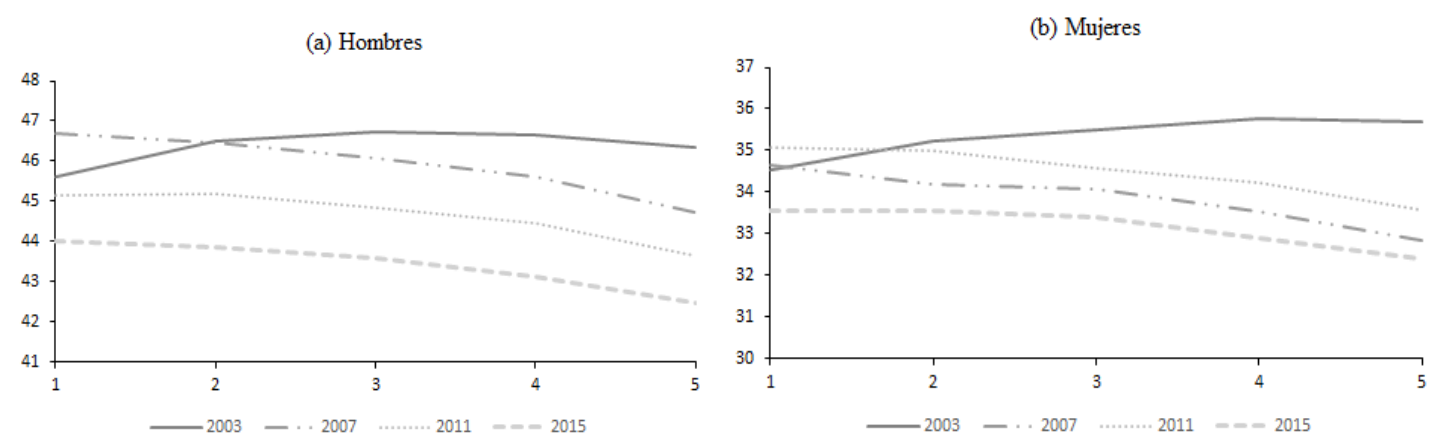

Nota: Horas predichas trabajadas por semana por quintil de ingreso per cápita familiar. Jefes de entre $15 \mathrm{y}$ 65 años, con respuestas válidas. Panel a: hombres; Panel b: mujeres Fuente: Elaboración propia en base a datos de la EPHC.

En resumen, se experimentó una reducción en la cantidad promedio de horas trabajadas por semana para casi todos los períodos analizados. La excepción a esta regla es el primero de ellos, que abarca los años 2003-2007, ya que presenta un leve aumento para los trabajadores de los dos quintiles más bajos, por lo que podría estar implicando un posible efecto reductor de la pobreza.

\subsubsection{Educación}


La estructura educativa en Argentina ha ido cambiando a lo largo de estos años, con una tendencia hacia niveles más altos. La proporción de trabajadores con primaria incompleta cayó de 7.2\% en 2003 a 3.9\% en 2015 (Tabla 4.6). Asimismo, el porcentaje de ocupados cuyo nivel de educación máximo es primaria completa y secundaria incompleta también cayó, en aproximadamente 6 y 2 puntos, respectivamente. En contraposición, secundaria completa, superior incompleto y superior completo, los niveles más altos de educación, experimentaron aumentos en el período completo. Esta tendencia de reducción de los niveles educativos bajos y aumento de los altos se mantuvo para todos los subperíodos de análisis, siendo el segundo, 2007-2011 el que experimentó los mayores cambios positivos.

Tabla 4.6. Ocupados por nivel educativo.

\begin{tabular}{lcccc}
\hline \hline & \multicolumn{4}{c}{ Promedio } \\
\cline { 2 - 5 } & $2003-\mathrm{II}$ & $2007-\mathrm{I}$ & $2011-\mathrm{I}$ & $2015-\mathrm{I}$ \\
\hline Primaria incompleta & 7.2 & 6.0 & 4.3 & 3.9 \\
Primaria completa & 22.6 & 20.6 & 18.4 & 17.1 \\
Secundaria incompleta & 19.0 & 17.9 & 17.5 & 17.1 \\
Secundaria completa & 20.2 & 23.2 & 24.9 & 27.0 \\
Superior incompleto & 13.2 & 14.0 & 14.3 & 13.8 \\
Superior completo & 17.7 & 18.3 & 20.5 & 21.0 \\
\hline
\end{tabular}

Nota: Porcentaje de ocupados entre 15 y 65 años por nivel educativo, con respuestas válidas. Fuente: Elaboración propia en base a datos de la EPHC.

\subsubsection{Fertilidad}

El efecto de las decisiones de fertilidad de los hogares afecta al ingreso per cápita familiar por tres canales: a través del denominador, que se ve afectado cuando el hogar decide tener más (o menos) hijos y a través de la ecuación (3.20), esto es de las decisiones de participar en el mercado laboral dada la cantidad de hijos y del coeficiente estimado de esta condición, $\hat{\lambda}^{\text {hijos }}$.

Por un lado, como lo muestra la Tabla 4.7, el número de hijos menores a 18 años promedio ha disminuido a través de los años, como parte del fenómeno denominado "bono demográfico". En 2003, el promedio de hijos de un hogar era 0.94. Para 2015, este valor cayó aproximadamente un $12 \%$, llegando a 0.83 . Analizando la evolución por etapas, si bien en la primera el promedio de hijos cayó (5.4\%), fue durante la segunda etapa en la que lo hizo con mayor fuerza (9\%). La última etapa, sin embargo, estuvo caracterizada por un leve aumento en el promedio de hijos, que alcanzó los 0.83 . 
La evolución de esta variable por quintil de ingreso per cápita familiar muestra un comportamiento similar al promedio, con excepción del primer quintil, que muestra un leve aumento del número de niños en el hogar durante el primer subperiodo, y caídas en el resto de los años. Para el período completo, si bien los quintiles más altos de la distribución son los que presentan una caída mayor en la cantidad de niños, los hogares de menores recursos han experimentado una caída importante.

Tabla 4.7. Número de hijos.

\begin{tabular}{lcccccccc}
\hline & \multicolumn{4}{c}{ Promedio } & \multicolumn{5}{c}{ Cambio (\%) } \\
\cline { 2 - 9 } & $2003-$ II & $2007-\mathrm{I}$ & $2011-\mathrm{I}$ & $2015-\mathrm{I}$ & $2007-2003$ & $2011-2007$ & $2015-2011$ & $2015-2003$ \\
\hline Quintil 1 & 2.11 & 2.12 & 2.01 & 2.00 & 0.8 & -5.6 & -0.1 & -4.9 \\
Quintil 2 & 1.51 & 1.37 & 1.30 & 1.38 & -9.6 & -5.1 & 6.4 & -8.8 \\
Quintil 3 & 0.95 & 0.86 & 0.83 & 0.89 & -9.3 & -2.9 & 6.9 & -5.9 \\
Quintil 4 & 0.59 & 0.56 & 0.47 & 0.51 & -4.4 & -16.9 & 8.1 & -14.2 \\
Quintil 5 & 0.35 & 0.33 & 0.27 & 0.24 & -6.6 & -18.2 & -11.2 & -32.2 \\
\hline Total & 0.94 & 0.89 & 0.81 & 0.83 & -5.4 & -9.0 & 2.0 & -12.1 \\
\hline
\end{tabular}

Nota: Promedio de hijos menores a 18 años por hogar en hogares con jefe de entre 15 y 65 años. Quintiles de ingreso per cápita familiar.

Fuente: Elaboración propia en base a datos de la EPHC.

Además de afectar el ingreso per cápita familiar a través de la cantidad de niños en el hogar, también lo hace mediante el cambio en el coeficiente $\hat{\lambda}^{\text {hijos }}$. El mismo puede verse en la Tabla A.2 en el anexo, que muestra los resultados de la estimación de horas trabajadas mediante el modelo de Tobit para jefes de hogar y cónyuges. Se supone que la cantidad de hijos en el hogar no interviene en las decisiones de participar en el mercado laboral de otros miembros. Si bien el efecto de un niño adicional en el hogar no es muy claro para los jefes, para cónyuges este es significativo y negativo, y ha ido cayendo a lo largo del tiempo, lo que implica un aumento promedio en las horas semanales que un trabajador dedica al mercado laboral, dada la existencia de niños en el hogar.

\subsubsection{Descomposición}

A pesar de que el análisis de las variables examinadas hasta ahora puede brindar una noción del efecto que estas tienen sobre la pobreza, no representan una prueba concluyente. La Tabla 4.8 muestra los resultados de realizar la descomposición con la metodología propuesta por Bourguignon et al (2005).

Los resultados de la descomposición de la tasa de pobreza a 4 dólares diarios PPA se muestran en las cuatro primeras columnas, mientras que las correspondientes a la línea 
de 2 dólares se encuentran en las siguientes cuatro. Durante el primer período, todos los efectos examinados parecen haber contribuido a la caída de la tasa de pobreza, que fue de 15 puntos. El efecto del cambio en los salarios es el de mayor preponderancia, ya que explica aproximadamente el $40 \%$ de la reducción. Dentro de este efecto, es posible diferenciar entre los cambios a los pagos de determinadas características de los trabajadores. Por un lado, los retornos a la educación han sido reductores de la pobreza, contribuyendo a la caída de este período en un $2.4 \%$. En menor medida que los cambios en los retornos a la educación, la evolución de la brecha de género también ha contribuido a la caída en la pobreza, en un $1.5 \%$. En la misma dirección contribuyeron también el cambio en los factores inobservables (y sus retornos), que están asociados con un $0.5 \%$ de la caída. Por otra parte, los efectos del aumento en las horas trabajadas para los ocupados y el correspondiente al empleo, que permite los cambios de estatus laboral fueron, luego del efecto de los salarios, los siguientes en importancia en la caída en la tasa de pobreza ( $3 \%$ y $5 \%$ respectivamente), seguido por los cambios en las características poblacionales, de $3 \%$ para los correspondientes a la estructura educativa y $4 \%$ para las decisiones de fertilidad.

Para el segundo período, en dónde la tasa de incidencia cayó 6.5 puntos, los efectos empleo y número de horas trabajadas revirtieron la dirección del cambio, contribuyendo al aumento de la pobreza en un 2\% y $1 \%$ respectivamente. El efecto de los salarios contribuyó a la reducción de la misma en aproximadamente un 16\%, porcentaje que no puede ser explicado en su totalidad por el cambio en la brecha salarial de género (reductor de pobreza en este período) y de los retornos a la educación (que contribuyeron al aumento de este indicador). Los cambios en las decisiones educativas y de fecundidad y el correspondiente a características inobservables, contribuyeron en este período a la caída de la pobreza en aproximadamente un 7\%, 1\% y 2\%, respectivamente.

Para el último período, en el que la caída de la pobreza se desaceleró (1.4 puntos en el total del período) solo los cambios en salarios, factores inobservables, educación y fecundidad mantuvieron su efecto reductor en la pobreza, mientras que los efectos relacionados de forma directa con el mercado laboral (horas y empleo) mantuvieron su efecto en la otra dirección. Una conclusión similar puede obtenerse al analizar la caída de la pobreza en el período completo. 
Tabla 4.8. Descomposición del cambio en la Pobreza.

Tasa de Pobreza.

\begin{tabular}{|c|c|c|c|c|c|c|c|c|}
\hline \multirow[b]{3}{*}{ Cambio observado } & \multicolumn{4}{|c|}{4 usd } & \multicolumn{4}{|c|}{2 usd } \\
\hline & 2003-2007 & 2007-2011 & 2011-2015 & 2003-2015 & 2003-2007 & $2007-2011$ & 2011-2015 & 2003-2015 \\
\hline & -15.1 & -6.5 & -1.4 & -23.0 & -9.9 & -4.7 & -1.4 & -16.0 \\
\hline \multicolumn{9}{|l|}{ Efectos } \\
\hline Salarios & -6.68 & -1.06 & -1.05 & -8.59 & -3.97 & -0.45 & -0.41 & -4.44 \\
\hline Retornos a la educación & -0.36 & 0.46 & 0.55 & 1.09 & -0.22 & 0.18 & 0.16 & 0.47 \\
\hline Brecha de género & -0.23 & -0.33 & 0.62 & 0.35 & -0.17 & -0.13 & 0.15 & 0.09 \\
\hline Inobservables & -0.08 & -0.15 & -0.17 & -0.51 & -0.25 & -0.21 & -0.17 & -0.61 \\
\hline Horas & -0.47 & 0.14 & 0.50 & 0.44 & -0.43 & 0.01 & 0.13 & 0.06 \\
\hline Empleo & -0.69 & 0.07 & 0.72 & 0.45 & -0.70 & -0.02 & 0.20 & -0.06 \\
\hline Educación & -0.49 & -0.49 & -0.13 & -1.16 & -0.38 & -0.28 & -0.05 & -0.81 \\
\hline Fecundidad & -0.57 & -0.06 & -0.38 & -1.00 & -0.43 & -0.03 & -0.14 & -0.75 \\
\hline
\end{tabular}

Nota: Descomposición de Bourguignon et al (2005) de la tasa de pobreza, calculada en base al ingreso per cápita familiar. Líneas de pobreza de 4 y 2 dólares diarios, PPA.

Fuente: Elaboración propia en base a datos de la EPHC.

Los resultados para la brecha y severidad de la pobreza no cuentan una historia diferente, por lo que con el objetivo de practicidad, se muestran en la Tabla A4 y A5 en el anexo.

Pese a que los resultados de esta metodología van en línea con lo encontrado en general por la literatura, sólo logran explicar una pequeña parte de la caída en los indicadores de pobreza en Argentina para el período de análisis. Dado que este tipo de descomposición intenta identificar el efecto que tienen sobre un indicador distributivo los cambios en ciertas variables o en los pagos a las mismas entre grupos, posiblemente las variaciones en la pobreza estén conducidas en su mayoría por cambios más generales, que afecten a toda la población.

\section{Comentarios finales}

La pobreza es posiblemente el problema de mayor relevancia social. Estudiar pobreza no solo es importante por tratarse de un fenómeno preocupante, sino también por sus potenciales consecuencias sobre otras variables económicas y sociales relevantes.

Este trabajo se ha propuesto analizar los cambios en la pobreza para el período comprendido entre el año 2003 y el año 2015 en Argentina para una serie de indicadores usuales de pobreza, explorando los determinantes de los cambios sufridos por éstos mediante la aplicación de metodologías de descomposición. Al mirar la evolución de los indicadores de pobreza, es posible identificar tres etapas claramente diferenciadas, de cuatro años cada una: una de reducción acelerada, entre el 2003 y el 2007; una de 
reducción moderada, entre 2007 y 2011 y finalmente una de estancamiento, entre 2011 y 2015.

La explicación de la evolución de la pobreza en estas etapas se abordó mediante tres metodologías distintas. De la primera de ellas, de carácter simple, se desprende que para el período completo, el efecto del crecimiento económico y del cambio en la desigualdad fue parejo: de los 23 puntos de caída de la tasa de pobreza a 4 dólares, el primero fue responsable del 53\%, mientras que el segundo lo fue del 47\%. Dado que dicha caída no fue homogénea a través de los años, es útil mirar la descomposición por períodos. En el primero de ellos, la caída de la pobreza, de aproximadamente 15 puntos, estuvo asociada fundamentalmente al crecimiento generalizado del ingreso, que explicó aproximadamente 10 puntos de la caída. El efecto redistribución en cambio, fue el mayor responsable de la reducción, más moderada, en la segunda etapa, dando cuenta de aproximadamente 4 de los 6.5 puntos de reducción. Finalmente, durante el último período, en el que la caída de la pobreza se estancó, de no haber sido por el efecto redistribución esta medida de hecho hubiese aumentado medio punto. Estos resultados son robustos al mirar la brecha o la severidad de la pobreza.

Dadas las limitaciones para aprender sobre los potenciales efectos que podrían tener las políticas públicas sobre los posibles determinantes del cambio en la pobreza, se realizó una segunda descomposición que permite separar el peso relativo que cada fuente de ingresos del hogar tiene sobre el cambio en los índices de pobreza. De este análisis, surge que, en el período completo los cambios en los ingresos laborales (asalariados, cuentapropistas y patronales) fueron los mayores responsables de la caída de la pobreza, explicando 17 de los 23 puntos de caída. Durante el primer período los ingresos laborales explican aproximadamente el $90 \%$ de la caída de 15 puntos en la tasa de pobreza a 4 dólares, seguido por las jubilaciones. Si bien los ingresos laborales continúan siendo los protagonistas de la caída en la segunda etapa, las jubilaciones y las transferencias estatales aportan a la reducción de 6.5 puntos de la pobreza en aproximadamente un $16 \%$ cada una. Finalmente, en el período de estancamiento, los ingresos laborales y las jubilaciones son los mayores responsables de la (casi nula) caída de la pobreza. A modo de robustez, se ha realizado este ejercicio sobre la brecha y la severidad de la pobreza, utilizando una línea más acorde a la pobreza "extrema". Los resultados no difieren a lo obtenido para la tasa de pobreza de 4 dólares diarios. 
Con el objetivo de profundizar el análisis de los determinantes del cambio en la pobreza, la tercera metodología se emplea para analizar la importancia que ciertos factores pueden tener sobre cambios en la pobreza, vía mercado laboral. Utilizando la metodología propuesta por Bourguignon et al (2005), para el período completo de análisis surge que la evolución de los salarios y de las características de la población, por un lado hacia mayores niveles de educación y por el otro hacia un menor número de niños en el hogar, son los principales responsables de la caída de la pobreza a 4 dólares diarios a PPA. Al mirar por tramos, durante los primeros cuatro años de análisis todos los factores analizados han contribuido a reducir la tasa de pobreza, siendo los efectos más grandes los que se relacionan directamente con el mercado laboral: los salarios, las horas trabajadas y el empleo. Durante la segunda etapa, las variables mayormente relacionadas con el crecimiento económico ya no pueden explicar caídas en la tasa de pobreza, mientras que el cambio en los salarios, las características poblaciones (educación y fertilidad) y el efecto de inobservables continúan manteniendo su efecto reductor de la pobreza, lo que parece mantenerse también para el último período analizado, con excepción del efecto del cambio en los factores inobservables.

Como en los ejercicios anteriores, estos resultados no cambian cuando se realiza la descomposición sobre los FGT(1) y FGT(2), ni cuando se analiza con un umbral de pobreza más bajo.

$\mathrm{Si}$ bien estos ejercicios permiten vislumbrar el efecto marginal del cambio en un determinante, es importante dar cuenta que todas las simulaciones realizadas sufren de inconsistencia de equilibrio, ya que se basan en contrafactuales de la distribución del ingreso que no reflejan un equilibrio económico general. Representan más bien un ejercicio estadístico, en el que se asume que es posible modificar un potencial determinante, por ejemplo los salarios, y mantener el resto constante. A pesar de ello, y de que no es posible una interpretación causal, este tipo de ejercicios no deja de ser útil para identificar ciertas regularidades empíricas que pueden ser tenidas en cuenta en la toma de decisiones de política pública. 


\section{Referencias}

Azevedo, J. P., Nguyen, M. C., y Sanfelice, V. 2012. ADECOMP: Stata module to estimate Shapley Decomposition by Components of a Welfare Measure. Statistical Software Components.

Azevedo, J. P., Inchauste, G., Olivieri, S., Saavedra, J., y Winkler, H. 2013. "Is labor income responsible for poverty reduction? A decomposition approach". Policy research Working Paper 6414, World Bank Publications.

Azevedo, J. P., Inchauste, G., y Sanfelice, V. 2013. "Decomposing the recent inequality decline in Latin America". Policy research Working Paper 6715, World Bank Publications.

Badaracco, N. 2014. "Fecundidad y Cambios Distributivos en América Latina". Documento de trabajo $\mathrm{n}^{\circ} 173$, CEDLAS.

Barros, R. P. D., Carvalho, M. D., Franco, S., y Mendonça, R. 2006. "Uma análise das principais causas da queda recente na desigualdade de renda brasileira. Econômica" v. 8, n. 1, 2006b, p. 117-147, Universidade Federal Fluminense.

Blinder, A. S. 1973. "Wage discrimination: reduced form and structural estimates". Journal of Human Resources, 436-455.

Bourguignon, F., Ferreira, F. H., y Lustig, N. Eds. 2005. The microeconomics of income distribution dynamics in East Asia and Latin America. New York: Oxford University Press.

CEDLAS 2017. Informe Breve. Marzo, 2017. Disponible en http://www.cedlas.econo.unlp.edu.ar/wp/wp-content/uploads/Informe-breve-Marzo2017.pdf último acceso 27 de Marzo de 2018.

Datt, G. y Ravallion, M. 1992. "Growth and redistribution components of changes in poverty measures: A decomposition with applications to Brazil and India in the 1980s". Journal of Development Economics, 382, 275-295.

Duflo, E. 2012. "Women Empowerment and Economic Development". Journal of Economic Literature 2012, 504, 1051-1079. 
Ferreira, F., y de Barros, R. P. 1999. "The slippery slope: explaining the increase in extreme poverty in urban Brazil, 1976-1996". "In the Microeconomics of Income Distribution Dynamics in East Asia and Latin America", eds Bourguignon, F., F. Ferreira y N. Lustig. New York: Oxford University Press.

Foster, J., Greer, J., y Thorbecke, E. 1984. “A class of decomposable poverty measures”. Econometrica, 761-766.

Gasparini, L., Alejo, J. y Parada, C. 2016 "Distributive implications of changing female employment: Latin America, 1990-2012". Manuscrito no publicado, Universidad Nacional de la Plata.

Gasparini, L. y Cruces G. 2008. "A Distribution in Motion: The Case of Argentina". CEDLAS, documento de trabajo $\mathrm{n}^{\mathrm{0}} 78$.

Gasparini, L., Cicowiez, M. y Sosa Escudero, W. 2013. Pobreza y Desigualdad en América Latina: Conceptos, herramientas y aplicaciones. Buenos Aires: Editorial Temas.

Gasparini, L., y Marchionni, M. 2015. Bridging Gender Gaps? The Rise and Deceleration of Female Labor Force Participation in Latin America. CEDLAS, Universidad Nacional de La Plata, Argentina.

Gasparini, L., Marchionni, M. y Sosa Escudero, W. 2005. "Characterization of inequality changes through microeconometric decomposition. The case of Great Buenos Aires". "In the Microeconomics of Income Distribution Dynamics in East Asia and Latin America", eds Bourguignon, F., F. Ferreira y N. Lustig. New York: Oxford University Press.

Gasparini, L., Alejo, J. y Parada, C. 2016 "Distributive implications of changing female employment: Latin America, 1990-2012". Manuscrito no publicado.

Inchauste, G., Azevedo, J. P., Essama-Nssah, B., Olivieri, S., Van Nguyen, T., SaavedraChanduvi, J., y Winkler, H. (2014). Understanding changes in poverty. World Bank Publications.

Juhn, C., Murphy, K. M., y Pierce, B. 1993. "Wage inequality and the rise in returns to skill”. Journal of Political Economy, 1013, 410-442.

Kolenikov, S., y Shorrocks, A. 2000. "Poverty Trends in Russia During the transition". CEPR, manuscrito. 
Mincer, J. 1958. "Investment in human capital and personal income distribution”. Journal of political economy, 664, 281-302.

Lustig, N., Lopez-Calva, L. F., y Ortiz-Juarez, E. 2013. "Declining inequality in Latin America in the 2000s: the cases of Argentina, Brazil, and Mexico". World Development, 44, 129-141.

Oaxaca, R. 1973. "Male-female wage differentials in urban labor markets". International Economic Review, 693-709.

Parada, C. 2014. "Empleo femenino, pobreza y desigualdad. Un anáalisis de microdescomposiciones. Uruguay 1991-2012”. Documento de trabajo n 174 , CEDLAS.

Tornarolli, L. 2018. "Series Comparables de Indigencia y Pobreza: Una Propuesta Metodológica". Documento de trabajo n²26, CEDLAS.

Vargas, J., y Garriga, S. 2015. "Explaining inequality and poverty reduction in Bolivia". Documento de trabajo $n^{\circ}$ 15/265, Fondo Monetario Internacional. 
ANEXO

Tabla A1. Ecuación del logartimo del salario horario.

\begin{tabular}{|c|c|c|c|c|c|c|c|c|c|c|c|c|}
\hline \multirow{2}{*}{$\begin{array}{l}\text { Log salario horario } \\
\text { Ecuación de salarios }\end{array}$} & \multicolumn{4}{|c|}{ Jefes } & \multicolumn{4}{|c|}{ Conyuges } & \multicolumn{4}{|c|}{ Otros } \\
\hline & 2003 & 2007 & 2011 & 2015 & 2003 & 2007 & 2011 & 2015 & 2003 & 2007 & 2011 & 2015 \\
\hline primaria completa & $0.165^{* * *}$ & $0.226 * * *$ & $0.196 * * *$ & $0.171^{* * *}$ & $0.199^{* * *}$ & $0.176^{* * *}$ & $0.210^{* * *}$ & $0.183^{* * *}$ & $0.252^{* * *}$ & $0.181^{* * *}$ & $0.109 * * *$ & $0.110^{* * *}$ \\
\hline & $(0.0265)$ & (0.0198) & $(0.0224)$ & $(0.0236)$ & $(0.0514)$ & $(0.0360)$ & (0.0398) & (0.0398) & $(0.0495)$ & $(0.0337)$ & $(0.0373)$ & $(0.0384)$ \\
\hline secundaria incompleta & $0.311^{* * *}$ & $0.378^{* * *}$ & $0.318^{* * *}$ & $0.262^{* * *}$ & $0.305^{* * *}$ & $0.328^{* * *}$ & $0.342^{* * *}$ & $0.261^{* * *}$ & $0.318^{* * *}$ & $0.243^{* * *}$ & $0.217^{* * *}$ & $0.141^{* * *}$ \\
\hline & $(0.0286)$ & $(0.0210)$ & $(0.0239)$ & $(0.0250)$ & $(0.0557)$ & $(0.0381)$ & $(0.0416)$ & $(0.0416)$ & $(0.0471)$ & (0.0319) & $(0.0355)$ & $(0.0368)$ \\
\hline secundaria completa & $0.553^{* * *}$ & $0.586^{* * *}$ & $0.534^{* * *}$ & $0.439^{* * *}$ & $0.494^{* * *}$ & $0.614^{* * *}$ & $0.597^{* * *}$ & $0.444^{* * *}$ & $0.531^{* * *}$ & $0.469 * * *$ & $0.424^{* * *}$ & $0.334^{* * *}$ \\
\hline & $(0.0308)$ & $(0.0214)$ & $(0.0247)$ & $(0.0257)$ & (0.0613) & $(0.0384)$ & $(0.0412)$ & (0.0419) & $(0.0499)$ & $(0.0330)$ & $(0.0371)$ & $(0.0382)$ \\
\hline universitario incompleto & $0.797^{* * *}$ & $0.801 * * *$ & $0.690^{* * *}$ & $0.609 * * *$ & $0.719 * * *$ & $0.822^{* * *}$ & $0.718^{* * *}$ & $0.602 * * *$ & $0.697 * * *$ & $0.636^{* * *}$ & $0.559 * * *$ & $0.523^{* * *}$ \\
\hline & $(0.0307)$ & $(0.0225)$ & $(0.0242)$ & $(0.0256)$ & $(0.0749)$ & $(0.0469)$ & $(0.0472)$ & $(0.0478)$ & $(0.0475)$ & $(0.0321)$ & $(0.0352)$ & $(0.0353)$ \\
\hline universitario completo & $1.144^{* * *}$ & $1.155^{* * *}$ & $1.031^{* * *}$ & $0.872^{* * *}$ & $0.992 * * *$ & $1.209 * * *$ & $1.154^{* * *}$ & $0.920^{* * *}$ & $1.113^{* * *}$ & $0.989 * * *$ & $0.880^{* * *}$ & $0.757^{* * *}$ \\
\hline & $(0.0371)$ & $(0.0234)$ & $(0.0281)$ & $(0.0285)$ & $(0.104)$ & $(0.0559)$ & $(0.0561)$ & $(0.0556)$ & (0.0568) & $(0.0371)$ & $(0.0407)$ & $(0.0417)$ \\
\hline hombre & $0.192 * * *$ & $0.183^{* * *}$ & $0.220^{* * *}$ & $0.147^{* * *}$ & $-0.275^{* * *}$ & -0.0134 & 0.0107 & $-0.0821 *$ & $0.112 * * *$ & $0.174^{* * *}$ & $0.152^{* * *}$ & $0.112^{* * *}$ \\
\hline & (0.0348) & $(0.0283)$ & $(0.0254)$ & $(0.0242)$ & $(0.0879)$ & (0.0599) & $(0.0520)$ & (0.0488) & $(0.0246)$ & $(0.0167)$ & $(0.0175)$ & $(0.0167)$ \\
\hline edad & $0.0528^{* * *}$ & $0.0151^{* *}$ & $0.0338^{* * *}$ & $0.0181^{* * *}$ & $0.0243^{*}$ & $0.0277^{* * *}$ & 0.0109 & 0.0107 & $0.0735 * * *$ & $0.0526 * * *$ & $0.0400^{* * *}$ & $0.0372^{* * *}$ \\
\hline & (0.00864) & (0.00623) & $(0.00652)$ & $(0.00586)$ & $(0.0126)$ & (0.00917) & $(0.00862)$ & (0.00812) & $(0.00910)$ & $(0.00576)$ & $(0.00637)$ & $(0.00610)$ \\
\hline edad2 & $-0.000497^{* * *}$ & $-5.55 e-05$ & $-0.000338^{* * *}$ & $-0.000138^{*}$ & -0.000131 & $-0.000207^{*}$ & $-3.50 e-05$ & $-3.55 e-05$ & $-0.000808^{* * *}$ & $-0.000528^{* * *}$ & $-0.000387^{* * *}$ & $-0.000370^{* * *}$ \\
\hline & $(0.000109)$ & $(7.87 e-05)$ & (8.17e-05) & $(7.26 e-05)$ & $(0.000153)$ & (0.000112) & (0.000106) & $(9.75 e-05)$ & $(0.000121)$ & (7.67e-05) & (8.33e-05) & (7.86e-05) \\
\hline menor18 & & & & & & & & & $-0.110^{*}$ & $-0.103^{* * *}$ & $-0.0947^{*}$ & 0.0116 \\
\hline & & & & & & & & & $(0.0641)$ & $(0.0392)$ & $(0.0514)$ & $(0.0528)$ \\
\hline pampeana & $-0.147^{* * *}$ & $-0.102^{* * *}$ & $-0.110^{* * *}$ & $-0.0541^{* * *}$ & $-0.186^{* * *}$ & $-0.0938^{* * *}$ & $-0.0750^{* * *}$ & $-0.0527^{* * *}$ & $-0.191^{* * *}$ & $-0.125^{* * *}$ & $-0.112 * * *$ & $-0.0635^{* * *}$ \\
\hline & $(0.0193)$ & $(0.0150)$ & $(0.0147)$ & $(0.0125)$ & $(0.0312)$ & $(0.0239)$ & $(0.0228)$ & (0.0196) & $(0.0254)$ & $(0.0184)$ & $(0.0190)$ & $(0.0168)$ \\
\hline Cuyo & $-0.314^{* * *}$ & $-0.241^{* * *}$ & $-0.250^{* * *}$ & $-0.158^{* * *}$ & $-0.311^{* * *}$ & $-0.257^{* * *}$ & $-0.286 * * *$ & $-0.165^{* * *}$ & $-0.346 * * *$ & $-0.260^{* * *}$ & $-0.338^{* * *}$ & $-0.262^{* * *}$ \\
\hline & $(0.0241)$ & $(0.0199)$ & $(0.0190)$ & (0.0169) & $(0.0418)$ & $(0.0322)$ & (0.0306) & $(0.0268)$ & $(0.0318)$ & $(0.0237)$ & $(0.0241)$ & $(0.0204)$ \\
\hline NOA & $-0.400^{* * *}$ & $-0.389 * * *$ & $-0.330^{* * *}$ & $-0.277^{* * *}$ & $-0.456 * * *$ & $-0.330^{* * *}$ & $-0.337^{* * *}$ & $-0.292^{* * *}$ & $-0.511^{* * *}$ & $-0.487^{* * *}$ & $-0.456 * * *$ & $-0.417^{* * *}$ \\
\hline & $(0.0225)$ & $(0.0174)$ & $(0.0165)$ & $(0.0142)$ & $(0.0360)$ & $(0.0289)$ & $(0.0260)$ & $(0.0220)$ & $(0.0276)$ & $(0.0197)$ & $(0.0200)$ & $(0.0167)$ \\
\hline Patagonia & $0.194^{* * *}$ & $0.328 * * *$ & $0.284^{* * *}$ & $0.334^{* * *}$ & $0.172^{* * *}$ & $0.296 * * *$ & $0.239 * * *$ & $0.318^{* * *}$ & $0.166 * * *$ & $0.272^{* * *}$ & $0.166^{* * *}$ & $0.227^{* * *}$ \\
\hline & $(0.0267)$ & $(0.0172)$ & $(0.0163)$ & (0.0148) & $(0.0445)$ & $(0.0276)$ & $(0.0260)$ & $(0.0230)$ & (0.0410) & $(0.0223)$ & $(0.0230)$ & $(0.0218)$ \\
\hline NEA & $-0.496^{* * *}$ & $-0.470^{* * *}$ & $-0.408^{* * *}$ & $-0.327^{* * *}$ & $-0.486^{* * *}$ & $-0.473^{* * *}$ & $-0.469 * * *$ & $-0.307^{* * *}$ & $-0.593^{* * *}$ & $-0.556^{* * *}$ & $-0.495 * * *$ & $-0.410^{* * *}$ \\
\hline & $(0.0284)$ & (0.0195) & $(0.0190)$ & $(0.0177)$ & $(0.0450)$ & $(0.0324)$ & $(0.0290)$ & $(0.0280)$ & $(0.0390)$ & $(0.0251)$ & $(0.0247)$ & $(0.0232)$ \\
\hline constante & $1.463^{* * *}$ & $2.556 * * *$ & $2.300^{* * *}$ & $2.763^{* * *}$ & $2.491^{* * *}$ & $2.392^{* * *}$ & $2.865^{* * *}$ & $3.052^{* * *}$ & $1.018^{* * *}$ & $1.776^{* * *}$ & $2.248^{* * *}$ & $2.447^{* * *}$ \\
\hline & $(0.223)$ & $(0.159)$ & $(0.168)$ & $(0.155)$ & $(0.387)$ & $(0.260)$ & $(0.239)$ & $(0.234)$ & $(0.215)$ & $(0.131)$ & (0.149) & $(0.151)$ \\
\hline Ecuación de selección & & & & & & & & & & & & \\
\hline primaria completa & $0.0798^{* *}$ & 0.0494 & $0.148^{* * *}$ & $0.194^{* * *}$ & 0.0716 & -0.00442 & 0.0754 & $0.137^{* * *}$ & $0.310^{* * *}$ & $0.347^{* * *}$ & $0.373^{* * *}$ & $0.610^{* * *}$ \\
\hline & $(0.0340)$ & $(0.0304)$ & $(0.0343)$ & $(0.0371)$ & $(0.0445)$ & (0.0394) & $(0.0473)$ & $(0.0507)$ & $(0.0471)$ & $(0.0406)$ & $(0.0457)$ & $(0.0472)$ \\
\hline secundaria incompleta & $0.156^{* * *}$ & $0.0974^{* * *}$ & $0.248^{* * *}$ & $0.320^{* * *}$ & $0.138^{* * *}$ & $0.0806^{*}$ & $0.166^{* * *}$ & $0.239 * * *$ & $0.332 * * *$ & $0.392 * * *$ & $0.499 * * *$ & $0.737^{* * *}$ \\
\hline & $(0.0370)$ & $(0.0328)$ & $(0.0366)$ & $(0.0391)$ & $(0.0479)$ & (0.0419) & $(0.0493)$ & $(0.0525)$ & $(0.0450)$ & (0.0379) & $(0.0425)$ & $(0.0439)$ \\
\hline secundaria completa & $0.299 * * *$ & $0.206 * * *$ & $0.359 * * *$ & $0.419^{* * *}$ & $0.319^{* * *}$ & $0.213^{* * *}$ & $0.268^{* * *}$ & $0.371^{* * *}$ & $0.432 * * *$ & $0.455^{* * *}$ & $0.612^{* * *}$ & $0.815^{* * *}$ \\
\hline & $(0.0372)$ & $(0.0323)$ & $(0.0352)$ & $(0.0374)$ & $(0.0460)$ & $(0.0400)$ & $(0.0469)$ & (0.0499) & $(0.0458)$ & $(0.0381)$ & $(0.0424)$ & $(0.0429)$ \\
\hline universitario incompleto & $0.311^{* * *}$ & $0.161^{* * *}$ & $0.299 * * *$ & $0.407^{* * *}$ & $0.481^{* * *}$ & $0.400^{* * *}$ & $0.426 * * *$ & $0.537^{* * *}$ & $0.487^{* * *}$ & $0.542^{* * *}$ & $0.682^{* * *}$ & $0.822 * * *$ \\
\hline & $(0.0450)$ & $(0.0392)$ & $(0.0423)$ & $(0.0437)$ & $(0.0568)$ & $(0.0487)$ & $(0.0554)$ & $(0.0575)$ & $(0.0501)$ & $(0.0427)$ & $(0.0472)$ & $(0.0480)$ \\
\hline universitario completo & $0.567^{* * *}$ & $0.321 * * *$ & $0.562^{* * *}$ & $0.609^{* * *}$ & $1.032^{* * *}$ & $0.780^{* * *}$ & $0.882^{* * *}$ & $0.940^{* * *}$ & $0.698^{* * *}$ & $0.696 * * *$ & $0.824^{* * *}$ & $1.006^{* * *}$ \\
\hline & $(0.0406)$ & $(0.0343)$ & $(0.0374)$ & (0.0391) & $(0.0479)$ & $(0.0415)$ & $(0.0483)$ & (0.0513) & $(0.0530)$ & $(0.0447)$ & $(0.0486)$ & $(0.0489)$ \\
\hline hombre & $0.589 * * *$ & $0.743 * * *$ & $0.749 * * *$ & $0.793^{* * *}$ & $1.048^{* * *}$ & $1.162^{* * *}$ & $1.284^{* * *}$ & $1.265^{* * *}$ & $0.398 * * *$ & $0.484^{* * *}$ & $0.503^{* * *}$ & $0.527^{* * *}$ \\
\hline & $(0.0273)$ & $(0.0216)$ & $(0.0211)$ & $(0.0196)$ & $(0.0481)$ & $(0.0372)$ & $(0.0365)$ & (0.0314) & $(0.0191)$ & $(0.0161)$ & $(0.0172)$ & $(0.0170)$ \\
\hline edad & $0.150^{* * *}$ & $0.156 * * *$ & $0.177^{* * *}$ & $0.178^{* * *}$ & $0.139 * * *$ & $0.165 * * *$ & $0.182 * * *$ & $0.180^{* * *}$ & $0.164 * * *$ & $0.173^{* * *}$ & $0.193 * * *$ & $0.206 * * *$ \\
\hline & $(0.00625)$ & $(0.00543)$ & $(0.00552)$ & $(0.00552)$ & $(0.00766)$ & $(0.00655)$ & $(0.00681)$ & (0.00686) & $(0.00630)$ & $(0.00522)$ & $(0.00538)$ & $(0.00524)$ \\
\hline edad2 & $-0.00198 * * *$ & $-0.00207^{* * *}$ & $-0.00230^{* * *}$ & $-0.00230^{* * *}$ & $-0.00176 * * *$ & $-0.00208 * * *$ & $-0.00230^{* * *}$ & $-0.00225 * * *$ & $-0.00209^{* * *}$ & $-0.00222^{* * *}$ & $-0.00245^{* * *}$ & $-0.00258^{* * *}$ \\
\hline & $(7.21 \mathrm{e}-05)$ & $(6.24 \mathrm{e}-05)$ & $(6.34 \mathrm{e}-05)$ & $(6.25 e-05)$ & (9.26e-05) & (7.87e-05) & (8.16e-05) & (8.05e-05) & $(8.57 e-05)$ & (7.09e-05) & (7.23e-05) & (7.03e-05) \\
\hline casado & $0.104^{* * *}$ & $0.0483^{* *}$ & -0.0109 & 0.0296 & & & & & -0.0442 & $-0.0404^{*}$ & 0.00192 & -0.0126 \\
\hline & $(0.0276)$ & $(0.0221)$ & $(0.0218)$ & $(0.0203)$ & & & & & (0.0291) & (0.0239) & (0.0249) & $(0.0243)$ \\
\hline numero hijos & $-0.0259 * * *$ & $-0.0392^{* * *}$ & $-0.0418^{* * *}$ & $-0.0525 * * *$ & $-0.0964 * * *$ & $-0.112^{* * *}$ & $-0.128^{* * *}$ & $-0.124^{* * *}$ & & & & \\
\hline & $(0.00778)$ & $(0.00695)$ & $(0.00781)$ & $(0.00814)$ & $(0.00899)$ & $(0.00788)$ & $(0.00880)$ & $(0.00924)$ & & & & \\
\hline menor18 & & & & & & & & & $-0.474^{* * *}$ & $-0.415^{* * *}$ & $-0.525 * * *$ & $-0.567^{* * *}$ \\
\hline & & & & & & & & & $(0.0419)$ & (0.0339) & $(0.0394)$ & $(0.0419)$ \\
\hline asiste & $-0.629^{* * *}$ & $-0.637^{* * *}$ & $-0.576^{* * *}$ & $-0.564^{* * *}$ & -0.0782 & -0.0722 & $-0.126^{* *}$ & $-0.0960 *$ & $-0.668 * * *$ & $-0.808^{* * *}$ & $-0.776 * * *$ & $-0.804^{* * *}$ \\
\hline & $(0.0531)$ & $(0.0437)$ & $(0.0443)$ & (0.0422) & $(0.0647)$ & $(0.0542)$ & (0.0549) & (0.0509) & $(0.0305)$ & $(0.0266)$ & $(0.0285)$ & $(0.0287)$ \\
\hline jefe ocupado & & & & & -0.00280 & $-0.0749 * *$ & 0.0292 & -0.00145 & $0.115^{* * *}$ & $0.0596 * * *$ & $0.0754^{* * *}$ & $0.0403^{* *}$ \\
\hline & & & & & $(0.0324)$ & $(0.0296)$ & (0.0308) & $(0.0293)$ & $(0.0210)$ & $(0.0176)$ & $(0.0186)$ & $(0.0181)$ \\
\hline conyuge ocupado & & & & & & & & & -0.0190 & $0.0388^{* *}$ & $-0.0365^{*}$ & -0.00320 \\
\hline & & & & & & & & & $(0.0222)$ & $(0.0187)$ & $(0.0201)$ & $(0.0197)$ \\
\hline pampeana & $-0.151^{* * *}$ & $-0.0890^{* * *}$ & $-0.112^{* * *}$ & -0.0252 & 0.0221 & 0.0284 & -0.00549 & 0.0263 & $-0.0964^{* * *}$ & $-0.108^{* * *}$ & $-0.178^{* * *}$ & $-0.0513^{* *}$ \\
\hline & & $(00267)$ & $(0.0276)$ & $(0.0253)$ & $(0.0317)$ & $(0.0295)$ & & $(0.0287)$ & & & & \\
\hline Cuyo & 0.0543 & -0.0260 & -0.00877 & $0.0719 * *$ & 0.0499 & 0.0327 & -0.0589 & 0.0295 & $-0.0777^{* *}$ & $-0.129^{* * *}$ & $-0.195 * * *$ & -0.00446 \\
\hline & $(0.0388)$ & $(0.0362)$ & $(0.0369)$ & $(0.0351)$ & $(0.0424)$ & $(0.0395)$ & $(0.0408)$ & $(0.0385)$ & $(0.0355)$ & $(0.0332)$ & $(0.0348)$ & $(0.0319)$ \\
\hline NOA & $-0.189^{* * *}$ & $-0.176 * * *$ & $-0.119 * * *$ & $-0.0668^{* *}$ & 0.0245 & $-0.111^{* * *}$ & -0.0399 & 0.0326 & $-0.184^{* * *}$ & $-0.268^{* * *}$ & $-0.255^{* * *}$ & $-0.0834^{* * *}$ \\
\hline & $(0.0320)$ & $(0.0294)$ & $(0.0305)$ & $(0.0279)$ & (0.0368) & $(0.0335)$ & $(0.0352)$ & (0.0323) & $(0.0297)$ & $(0.0266)$ & $(0.0285)$ & $(0.0257)$ \\
\hline Patagonia & $-0.0731^{*}$ & $-0.0808^{* * *}$ & -0.0128 & -0.0346 & $0.125^{* * *}$ & 0.0350 & $0.0828^{* *}$ & $0.0686^{* *}$ & $-0.118^{* * *}$ & $-0.118^{* * *}$ & $-0.156 * * *$ & $-0.149 * * *$ \\
\hline & $(0.0425)$ & $(0.0309)$ & $(0.0319)$ & (0.0299) & $(0.0460)$ & $(0.0341)$ & $(0.0356)$ & $(0.0342)$ & $(0.0448)$ & $(0.0313)$ & $(0.0335)$ & $(0.0326)$ \\
\hline NEA & $-0.314^{* * *}$ & $-0.182^{* * *}$ & $-0.191 * * *$ & $-0.179 * * *$ & $-0.108^{* *}$ & $-0.116^{* * *}$ & -0.0216 & $-0.135^{* * *}$ & $-0.390 * * *$ & $-0.414^{* * *}$ & $-0.357 * * *$ & $-0.311^{* * *}$ \\
\hline & $(0.0364)$ & $(0.0327)$ & $(0.0337)$ & (0.0329) & $(0.0428)$ & $(0.0374)$ & (0.0393) & $(0.0388)$ & $(0.0368)$ & $(0.0311)$ & $(0.0330)$ & $(0.0324)$ \\
\hline constante & $-2.450^{* * *}$ & $-2.455^{* * *}$ & $-2.958^{* * *}$ & $-3.134^{* * *}$ & $-3.043^{* * *}$ & $-3.254^{* * *}$ & $-3.649 * * *$ & $-3.775^{* * *}$ & $-3.288^{* * *}$ & $-3.219^{* * *}$ & $-3.692 * * *$ & $-4.291^{* * *}$ \\
\hline & $(0.132)$ & $(0.117)$ & (0.119) & $(0.122)$ & $(0.154)$ & $(0.133)$ & $(0.142)$ & $(0.146)$ & $(0.116)$ & $(0.0969)$ & $(0.103)$ & $(0.103)$ \\
\hline Obs & 21,038 & 29,589 & 28,364 & 29,326 & 14,542 & 19,939 & 18,407 & 18,840 & 23,938 & 33,498 & 30,121 & 32,010 \\
\hline Chi 2 & 3906 & 7981 & 5930 & 5610 & 1204 & 3019 & 2946 & 2754 & 1697 & 3673 & 2794 & 2996 \\
\hline Rho & 0.0661 & -0.261 & 0.158 & -0.0906 & -0.432 & -0.226 & -0.208 & -0.291 & 0.253 & 0.122 & 0.0609 & -0.00131 \\
\hline Sigma & 0.772 & 0.691 & 0.651 & 0.609 & 0.848 & 0.709 & 0.673 & 0.642 & 0.774 & 0.663 & 0.642 & 0.607 \\
\hline Lambda & 0.0511 & -0.180 & 0.103 & -0.0552 & -0.366 & -0.160 & -0.140 & -0.187 & 0.196 & 0.0808 & 0.0391 & -0.000796 \\
\hline
\end{tabular}

Errores estándar en paréntesis

${ }^{* * *} p<0.01,{ }^{* *} p<0.05,{ }^{*} p<0.1$

Nota: Estimación de Heckman en dos etapas. Trabajadores entre 15 y 65 años con respuestas válidas. Fuente: Elaboración propia en base a datos de la EPH. 
Tabla A2. Ecuación de horas trabajadas.

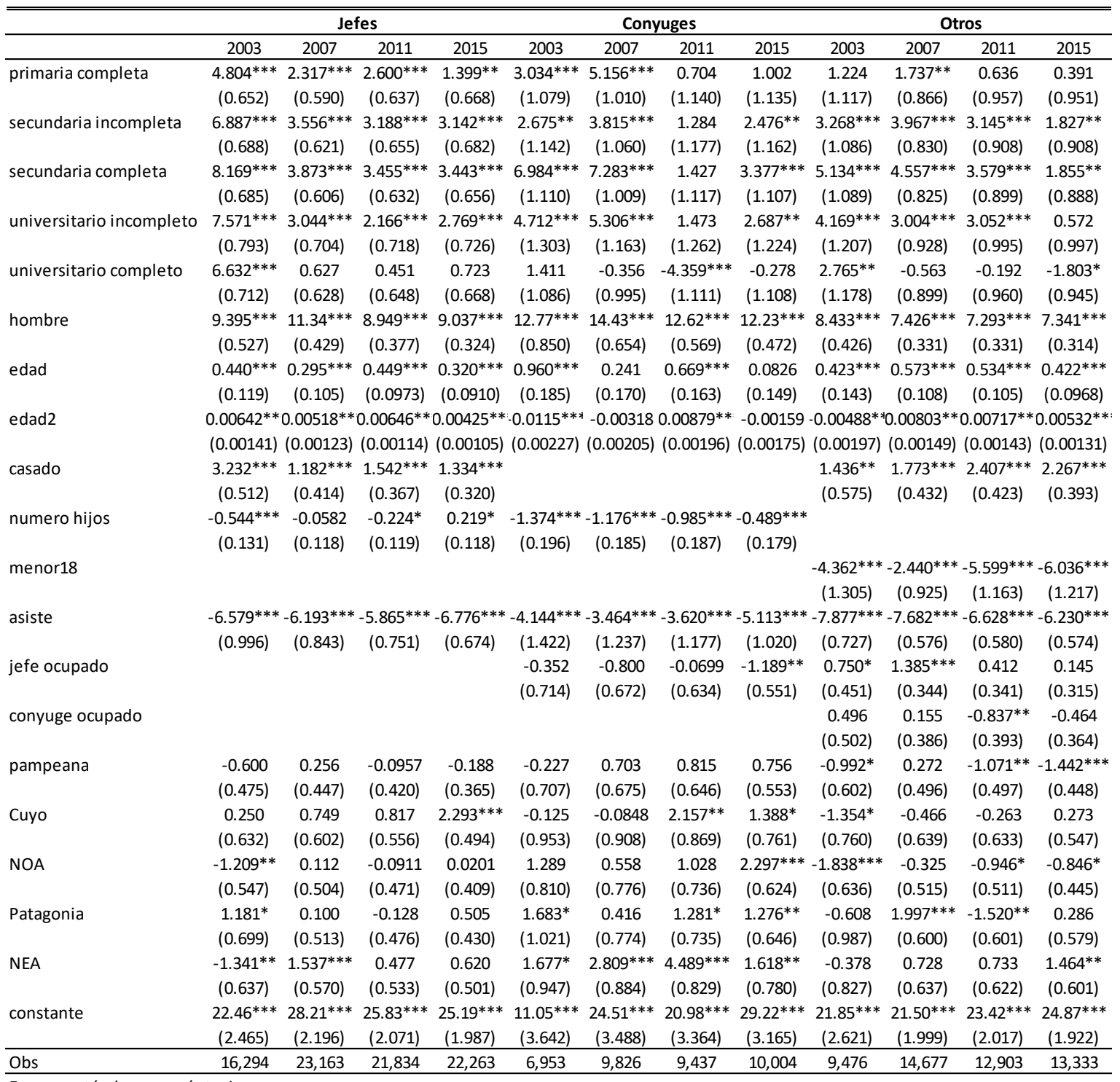

Errores estándar en paréntesis

$* * * p<0.01, * * p<0.05, * p<0.1$

Nota: Estimación de Tobit de las horas trabajadas. Trabajadores entre 15 y 65 años con respuestas válidas. Fuente: Elaboración propia en base a datos de la EPH. 
Tabla A.3. Descomposición por fuentes de ingreso.

Panel A. FGT(0)

\begin{tabular}{|c|c|c|c|c|c|c|c|c|}
\hline & \multicolumn{4}{|c|}{4 usd } & \multicolumn{4}{|c|}{2 usd } \\
\hline & 2003-2007 & $2007-2011$ & $2011-2015$ & $2003-2015$ & 2003-2007 & $2007-2011$ & 2011-2015 & $2003-2015$ \\
\hline Cambio observado & -15.1 & -6.5 & -1.4 & -23.0 & -9.9 & -4.7 & -1.4 & -16.0 \\
\hline Asalariados & -10.7 & -3.3 & -1.2 & -15.1 & -7.5 & -2.1 & -0.6 & -9.9 \\
\hline Patrones & -0.4 & -0.2 & 0.5 & 0.0 & -0.2 & -0.2 & 0.2 & 0.0 \\
\hline Cuenta propista & -1.4 & -0.3 & -0.3 & -2.1 & -1.1 & 0.0 & -0.2 & -1.4 \\
\hline Jubilaciones & -1.5 & -1.0 & -0.3 & -2.9 & -1.0 & -0.9 & -0.2 & -2.0 \\
\hline Capital & -0.1 & 0.0 & 0.2 & 0.2 & -0.1 & 0.0 & 0.1 & 0.2 \\
\hline Transferencias & -0.8 & 0.0 & 0.1 & -0.5 & -0.6 & -0.1 & 0.0 & -0.5 \\
\hline Tranferencias estatales & 0.8 & -1.1 & 0.0 & -0.1 & 1.2 & -1.1 & -0.2 & -0.5 \\
\hline Otros ingresos & -1.1 & -0.5 & -0.5 & -2.5 & -0.5 & -0.3 & -0.5 & -1.8 \\
\hline
\end{tabular}

Panel B. FGT(1)

\begin{tabular}{|c|c|c|c|c|c|c|c|c|}
\hline & \multicolumn{4}{|c|}{4 usd } & \multicolumn{4}{|c|}{2 usd } \\
\hline & 2003-2007 & 2007-2011 & 2011-2015 & $2003-2015$ & 2003-2007 & 2007-2011 & 2011-2015 & $2003-2015$ \\
\hline Cambio observado & -7.5 & -3.4 & -0.8 & -11.7 & -4.1 & -2.1 & -0.4 & -6.7 \\
\hline Asalariados & -5.8 & -1.5 & -0.4 & -7.4 & -3.6 & -0.9 & -0.1 & -4.2 \\
\hline Patrones & -0.2 & -0.1 & 0.2 & 0.0 & -0.1 & -0.1 & 0.1 & 0.0 \\
\hline Cuenta propista & -0.8 & 0.1 & -0.2 & -0.9 & -0.5 & 0.2 & -0.1 & -0.4 \\
\hline Jubilaciones & -0.7 & -0.7 & -0.1 & -1.5 & -0.4 & -0.5 & 0.0 & -0.9 \\
\hline Capital & -0.1 & 0.0 & 0.1 & 0.1 & 0.0 & 0.0 & 0.0 & 0.1 \\
\hline Transferencias & -0.5 & 0.0 & 0.0 & -0.4 & -0.4 & 0.0 & 0.0 & -0.3 \\
\hline Tranferencias estatales & 0.9 & -0.9 & -0.1 & -0.3 & 0.9 & -0.8 & -0.1 & -0.4 \\
\hline Otros ingresos & -0.4 & -0.2 & -0.4 & -1.3 & -0.1 & -0.1 & -0.3 & -0.7 \\
\hline
\end{tabular}

Panel C. FGT(2)

\begin{tabular}{|c|c|c|c|c|c|c|c|c|}
\hline & \multicolumn{4}{|c|}{4 usd } & \multicolumn{4}{|c|}{2 usd } \\
\hline & 2003-2007 & $2007-2011$ & $2011-2015$ & $2003-2015$ & 2003-2007 & $2007-2011$ & 2011-2015 & $2003-2015$ \\
\hline Cambio observado & -4.6 & -2.2 & -0.5 & -7.3 & -2.4 & -1.3 & -0.2 & -4.0 \\
\hline Asalariados & -3.8 & -0.9 & -0.1 & -4.6 & -2.3 & -0.5 & 0.1 & -2.5 \\
\hline Patrones & -0.1 & -0.1 & 0.1 & 0.0 & -0.1 & 0.0 & 0.1 & 0.0 \\
\hline Cuenta propista & -0.6 & 0.2 & -0.1 & -0.4 & -0.4 & 0.2 & -0.1 & -0.1 \\
\hline Jubilaciones & -0.4 & -0.5 & -0.1 & -1.0 & -0.2 & -0.4 & 0.0 & -0.5 \\
\hline Capital & 0.0 & 0.0 & 0.0 & 0.1 & 0.0 & 0.0 & 0.0 & 0.0 \\
\hline Transferencias & -0.4 & 0.0 & 0.0 & -0.3 & -0.3 & 0.0 & 0.0 & -0.2 \\
\hline Tranferencias estatales & 0.9 & -0.8 & -0.1 & -0.4 & 0.8 & -0.6 & 0.0 & -0.3 \\
\hline Otros ingresos & -0.1 & -0.1 & -0.3 & -0.8 & 0.1 & 0.0 & -0.2 & -0.4 \\
\hline
\end{tabular}

Nota: Descomposición de Acevedo et al (2012), a 2 y 4 dólares diarios PPA. Ingreso per cápita familiar. Panel a: tasa de incidencia de la pobreza. Panel b: brecha de la pobreza. Panel c: severidad de la pobreza. Fuente: Elaboración propia en base a datos de la EPHC. 
Tabla A4. Descomposición del cambio en la brecha de la Pobreza.

\begin{tabular}{|c|c|c|c|c|c|c|c|c|}
\hline \multirow[b]{3}{*}{ Cambio observado } & \multicolumn{4}{|c|}{4 usd } & \multicolumn{4}{|c|}{2 usd } \\
\hline & $2003-2007$ & 2007-2011 & 2011-2015 & $2003-2015$ & 2003-2007 & 2007-2011 & 2011-2015 & 2003-2015 \\
\hline & -7.5 & -3.4 & -0.8 & -11.7 & -4.1 & -2.1 & -0.4 & -6.7 \\
\hline \multicolumn{9}{|l|}{ Efectos } \\
\hline Salarios & -2.95 & -0.34 & -0.34 & -3.32 & -1.42 & -0.15 & -0.10 & -1.34 \\
\hline Retornos a la educación & -0.20 & 0.18 & 0.18 & 0.41 & -0.10 & 0.07 & 0.04 & 0.17 \\
\hline Brecha de género & -0.10 & -0.10 & 0.18 & 0.10 & -0.06 & -0.04 & 0.04 & 0.04 \\
\hline Inobservables & -0.25 & -0.10 & -0.09 & -0.38 & -0.19 & -0.06 & -0.03 & -0.22 \\
\hline Horas & -0.32 & 0.06 & 0.16 & 0.13 & -0.24 & 0.02 & 0.05 & 0.02 \\
\hline Empleo & -0.49 & 0.03 & 0.24 & 0.07 & -0.39 & -0.01 & 0.09 & -0.04 \\
\hline Educación & -0.24 & -0.20 & -0.03 & -0.56 & -0.10 & -0.11 & -0.01 & -0.30 \\
\hline Fecundidad & -0.31 & -0.02 & -0.15 & -0.50 & -0.18 & -0.02 & -0.05 & -0.28 \\
\hline
\end{tabular}

Nota: Descomposición de Bourguignon et al (2005) de la brecha de pobreza, calculada en base al ingreso per cápita familiar. Líneas de pobreza de 4 y 2 dólares diarios, PPA.

Fuente: Elaboración propia en base a datos de la EPHC.

Tabla A5. Descomposición del cambio en la severidad de la Pobreza.

\begin{tabular}{|c|c|c|c|c|c|c|c|c|}
\hline \multirow[b]{3}{*}{ Cambio observado } & \multicolumn{4}{|c|}{4 usd } & \multicolumn{4}{|c|}{2 usd } \\
\hline & 2003-2007 & $2007-2011$ & 2011-2015 & 2003-2015 & 2003-2007 & $2007-2011$ & 2011-2015 & 2003-2015 \\
\hline & -4.6 & -2.2 & -0.5 & -7.3 & -2.4 & -1.3 & -0.2 & -4.0 \\
\hline \multicolumn{9}{|l|}{ Efectos } \\
\hline Salarios & -1.66 & -0.18 & -0.15 & -1.71 & -0.74 & -0.07 & -0.04 & -0.64 \\
\hline Retornos a la educación & -0.11 & 0.09 & 0.07 & 0.21 & -0.04 & 0.03 & 0.02 & 0.08 \\
\hline Brecha de género & -0.06 & -0.05 & 0.07 & 0.05 & -0.03 & -0.02 & 0.02 & 0.02 \\
\hline Inobservables & -0.19 & -0.06 & -0.04 & -0.24 & -0.12 & -0.03 & -0.02 & -0.13 \\
\hline Horas & -0.23 & 0.03 & 0.08 & 0.04 & -0.15 & 0.01 & 0.02 & 0.00 \\
\hline Empleo & -0.38 & 0.00 & 0.12 & -0.01 & -0.26 & -0.01 & 0.05 & -0.04 \\
\hline Educación & -0.13 & -0.12 & -0.01 & -0.33 & -0.05 & -0.06 & 0.00 & -0.15 \\
\hline Fecundidad & -0.19 & -0.02 & -0.07 & -0.30 & -0.10 & -0.01 & -0.02 & -0.15 \\
\hline
\end{tabular}

Nota: Descomposición de Bourguignon et al (2005) de la severidad de pobreza, calculada en base al ingreso per cápita familiar. Líneas de pobreza de 4 y 2 dólares diarios, PPA.

Fuente: Elaboración propia en base a datos de la EPHC. 